\title{
Combined albumin and bicarbonate induces head-to-head sperm agglutination which physically prevents equine sperm-oviduct binding
}

\author{
Bart Leemans ${ }^{1}$, Bart M Gadella ${ }^{2,3}$, Tom A E Stout ${ }^{2,4}$, Edita Sostaric ${ }^{4}$, Catharina De Schauwer ${ }^{1}$, \\ Hilde Nelis ${ }^{1}$, Maarten Hoogewijs ${ }^{1}$ and Ann Van Soom ${ }^{1}$ \\ ${ }^{1}$ Department of Reproduction, Obstetrics and Herd Health, Faculty of Veterinary Medicine, Ghent University, \\ Belgium, Departments of ${ }^{2}$ Farm Animal Health, ${ }^{3}$ Biochemistry and Cell Biology and ${ }^{4}$ Equine Sciences, \\ Faculty of Veterinary Medicine, Utrecht University, Utrecht, The Netherlands
}

Correspondence should be addressed to B Leemans; Email: baleeman.leemans@ugent.be

\begin{abstract}
In many species, sperm binding to oviduct epithelium is believed to be an essential step in generating a highly fertile capacitated sperm population primed for fertilization. In several mammalian species, this interaction is based on carbohydrate-lectin recognition.

D-galactose has previously been characterized as a key molecule that facilitates sperm-oviduct binding in the horse. We used oviduct explant and oviduct apical plasma membrane (APM) assays to investigate the effects of various carbohydrates; glycosaminoglycans; lectins; S-S reductants; and the capacitating factors albumin, $\mathrm{Ca}^{2+}$ and $\mathrm{HCO}_{3}^{-}$on sperm-oviduct binding in the horse. Carbohydratespecific lectin staining indicated that $\mathbf{N}$-acetylgalactosamine, $\mathbf{N}$-acetylneuraminic acid (sialic acid) and D-mannose or D-glucose were the most abundant carbohydrates on equine oviduct epithelia, whereas D-galactose moieties were not detected. However, in a competitive binding assay, sperm-oviduct binding density was not influenced by any tested carbohydrates, glycosaminoglycans, lectins or D-penicillamine, nor did the glycosaminoglycans induce sperm tail-associated protein tyrosine phosphorylation. Furthermore, $\mathrm{N}$-glycosidase $\mathrm{F}$ (PNGase) pretreatment of oviduct explants and APM did not alter sperm-oviduct binding density. By contrast, a combination of the sperm-capacitating factors albumin and $\mathrm{HCO}_{3}^{-}$severely reduced ( $>\mathbf{1 0}$-fold) equine sperm-oviduct binding density by inducing rapid head-to-head agglutination, both of which events were independent of $\mathrm{Ca}^{2+}$ and an elevated pH (7.9). Conversely, neither albumin and $\mathrm{HCO}_{3}^{-}$nor any other capacitating factor could induce release of oviduct-bound sperm. In conclusion, a combination of albumin and $\mathrm{HCO}_{3}^{-}$markedly induced sperm head-to-head agglutination which physically prevented stallion sperm to bind to oviduct epithelium.
\end{abstract}

Reproduction (2016) 151 313-330

\section{Introduction}

Sperm storage after mating is a female reproductive tract phenomenon that has been observed in various animals with the presumed aim to preserving sperm fertilizing capacity in species in which mating and ovulation are poorly synchronized (Holt 2011). In the mare (Bader 1982, Scott et al. 2000) and many other mammals (rabbit (Harper 1973), pig (Hunter 1981), sheep (Hunter \& Nichol 1983), mouse (Suarez 1987), cattle (Hunter \& Wilmut 1984) and hamster (Yanagimachi \& Chang 1963)), an oviductal sperm reservoir is established at the uterotubal junction and the caudal part of the oviductal isthmus. This sperm reservoir contains spermatozoa bound to the epithelial surface by their apical head region. Most of the bound sperm are found in pockets formed by mucosal folds. The precise identity of molecules involved in sperm-oviduct interaction is not clear, but there are indications that the interaction in several mammals is mediated by carbohydrate ligands in a species-specific manner (Suarez 2001). In general, spermatozoa contain lectin-like receptors on their plasma membrane with affinity for carbohydrate moieties found on the surface of oviduct epithelial cells. Interactions between the two can therefore be studied using competitive carbohydrate-lectin binding assays. It has also been hypothesized that, when ovulation is imminent, oviduct-bound spermatozoa become capacitated and subsequently release. The releasing factor needs to have either a stronger affinity for the carbohydrateligand receptors on the sperm plasma membrane, with sperm release as a result of a competitive interaction as shown in cattle (Talevi \& Gualtieri 2001, Sostaric et al. 2005, Gualtieri et al. 2010), or enzymatic activity capable of disturbing the lectin recognition site or substrate. 
Bull spermatozoa actively bind via the apical part of the sperm head surface to the oviduct epithelium (Hunter et al., 1991). Only non-capacitated bovine spermatozoa are able to bind to oviductal epithelium in vitro (Lefebvre et al. 1995a, Gualtieri \& Talevi 2000). Importantly, the bound spermatozoa appear to remain in a rather quiescent state in the early pre-ovulatory stage oviduct. This has been demonstrated by incubation of rabbit, bull, boar and stallion spermatozoa with the apical plasma membranes (APMs) of preovulatory oviductal epithelial cells; binding to oviductal epithelium prolonged sperm longevity (Smith \& Nothnick 1997, Boilard et al. 2002) by maintaining low cytoplasmic $\mathrm{Ca}^{2+}$ levels (Dobrinski et al. 1997). Oviduct binding of non-capacitated bull sperm can be inhibited by fucose and fucoidan (a sulfated polysaccharide that predominantly consists of fucose) (Lefebvre et al. 1997, Talevi \& Gualtieri 2001, Sostaric et al. 2005), while pretreatment of bovine oviduct explants with fucosidase significantly reduces sperm binding (Lefebvre et al. 1997). Not only the presence of fucose but also its position within the complex carbohydrate moieties is important for functional sperm-oviduct binding. For instance, only trisaccharide Lewis A $(\alpha-1$-Fuc $(1,4)-\beta$-D-Gal $(1,3)$-d-GlcNAc) significantly reduced binding of spermatozoa to oviduct epithelia, whereas other fucose-containing oligosaccharides failed to influence sperm-oviduct binding (Suarez et al. 1998, Sostaric et al. 2005). A competitive carbohydrate-binding inhibition assay, using fetuin and sialic acid individually, was successfully used to block hamster sperm-oviduct binding (DeMott et al., 1995). In pigs, the major inhibitory effect could be mimicked by biantennary structures containing a mannose core with six sialylated lactosamines at one or more termini. In pigs, as in cattle, binding to carbohydrate moieties was specific; different isomers of the specific motif did not bind sperm (Kadirvel et al. 2012).

At the late pre-ovulatory stage, it is thought that oviduct-bound sperm undergo final maturation or capacitation and are released from oviduct epithelial cells by undergoing plasma membrane changes and achieving hyperactivated motility at various rates (Suarez 1998, 2008a). In many mammals, this release coincides with raised levels of capacitation factors (Suarez 2008b). In cattle, sulfated glycosaminoglycans both inhibit sperm to bind to the oviduct and trigger the sperm to release from the oviduct epithelium. These sulfated moieties facilitate a reduction in fucose binding by spermatozoa, which is regulated by direct competition. In fact, dextran sulfate and heparin, but not dextran and $N$ desulfated heparin, are powerful inhibitors of sperm-oviduct binding and trigger sperm release from oviduct epithelium as well (Talevi \& Gualtieri 2001). This suggests that sulfated glycosaminoglycans released into the bovine oviduct near the time of ovulation display a stronger affinity for sperm plasma membrane receptors than fucose moieties expressed on the oviduct membrane (Sostaric et al. 2005).

In addition, disulfide reductants like D-penicillamine inhibit sperm-oviduct binding and facilitate sperm release from the oviduct epithelium. It was suggested that reversible adhesion of bull spermatozoa to the oviduct epithelium is modulated by redox control of sperm surface protein sulfhydryls (Gualtieri et al. 2009).

Much less is known about sperm-oviduct epithelium binding in the horse. Inhibition of stallion sperm binding to oviduct epithelial monolayers has been reported after adding fetuin, asialofetuin or D-galactose to the culture medium (D-galactose gave the most prominent effects; Dobrinski et al. 1996a). Moreover, since galactosebinding proteins have been observed on the rostral and post-acrosomal regions of the sperm head of noncapacitated stallion spermatozoa (Sabeur \& Ball 2007), the authors concluded that D-galactose was the key molecule facilitating the binding of non-capacitated spermatozoa to oviduct epithelium in the horse (Lefebvre et al. 1995b, Dobrinski et al. 1996a). Nevertheless, equine oviduct epithelium expresses very few D-galactose moieties (Desantis et al. 2004, 2005), and it is more likely that other, as yet undefined, factors are involved in regulating binding of non-capacitated stallion sperm to the oviduct epithelium.

For release of sperm from the epithelium lining the equine oviduct, high concentrations of sulfated glycosaminoglycans in oviductal fluid (originating from the ovulatory follicle or secreted from the oviduct epithelium) may be important (Varner et al. 1991). Glycosaminoglycans and disulfide reductants have been reported to play a role in bovine sperm-oviduct binding and sperm release from the epithelium (Gualtieri et al. 2010). We, therefore, decided to investigate the involvement of various carbohydrates in the regulation of equine sperm-oviduct binding and release, as well as that of known capacitation factors such as albumin, $\mathrm{Ca}^{2+}$ and $\mathrm{HCO}_{3}^{-}$ions.

\section{Materials and methods}

\section{Chemicals and reagents}

Dulbecco's PBS (DPBS), HBS, fetal bovine serum (FBS) (Batch: 07G8814F) and DMEM/Nutrient Mixture F-12 (DMEM/F12) were purchased from Gibco Life Technologies. Various carbohydrates and glycosaminoglycans (D-galactose, $\mathrm{N}$-acetylgalactosamine, $\mathrm{N}$-acetylglucosamine, fetuin, asialofetuin, D-fucose, fucoidan, D-mannose, mannan, $\mathrm{N}$-acetylneuraminic (sialic) acid, chondroitin sulfate, dextran sulfate, heparan sulfate, heparin, hyaluronic acid and keratan sulfate), D-penicillamine, fatty acid-free BSA (A9418; cell culture tested), ethylene glycol tetraacetic acid (EGTA) and all chemicals not otherwise listed were obtained from SigmaAldrich. Various lectins (non-fluorescein conjugated and fluorescein conjugated): Arachis hypogaea (peanut) agglutinin (PNA), Dolichos biflorus agglutinin (DBA), Helix pomatia 
agglutinin (HPA), Triticum vulgare (wheat germ) agglutinin (WGA), Ulex europaeus agglutinin (UEA 1), Sambucus nigra agglutinin (SNA), Canavalia ensiformis agglutinin (Con A), Lens culinaris agglutinin (LCA) and Pisum sativum (pea) agglutinin (PSA) were purchased from Labconsult SPRL (Vector Labs, Brussels, Belgium). Hoechst 33342 and Alexa Fluor 488-conjugated goat anti-mouse antibody were obtained from Molecular Probes (Ghent, Belgium). Monoclonal 4G10 Platinum, anti-phosphotyrosine mouse antibodies were obtained from Millipore (Overijse, Belgium). Protease inhibitors (cOmplate, Mini, EDTA-free) were purchased from Roche.

\section{Animals \\ Oviducts were collected at a local slaughterhouse (Euro Meat Group, Moeskroen, Belgium) from healthy Warmblood mares aged between 5 and 22 years and without any visible reproductive tract pathology. Only oviducts from mares with growing follicles and without a corpus luteum on the ovaries in combination with estrous oedema in the uterine wall, indicating that the mare was in estrus, were used for this study. \\ Preparation of oviduct explants and isolation of oviduct APMs}

Five oviducts per experiment were prepared for oviduct explant culture, as previously described by Nelis et al. (2014). Briefly, oviducts from mares in early estrus were dissected free of extraneous connective tissue, clamped at both ends and transported on ice in sterile $0.9 \%$ saline containing $50 \mu \mathrm{g} / \mathrm{ml}$ gentamycin. Upon arrival at the laboratory, the oviducts were washed in DPBS, and the epithelial cells were harvested by scraping the ampullary-isthmic mucosa of the longitudinally incised oviduct. The harvested cellular material was transferred to a tube containing HEPES-buffered Tyrode's albumin pyruvate lactate (TALP) $(10 \mu \mathrm{g} / \mathrm{ml}$ gentamycin sulfate, $10 \mathrm{mM} \mathrm{HEPES}$ and $3 \mathrm{mg} / \mathrm{ml} \mathrm{BSA}$; based on Rath et al. (1999)) and left to settle for $10 \mathrm{~min}$, after which the cell pellet was resuspended in $3 \mathrm{ml}$ of fresh HEPES-buffered TALP washing medium. The process of sedimentation was repeated twice. The time span from slaughter of mares to seeding of the cells was $\sim 3-4$ h. Next, the harvested cellular material was washed and cultured overnight in DMEM/F12 with $10 \%$ FBS at $38.5{ }^{\circ} \mathrm{C}$ in a humidified atmosphere of $5 \% \mathrm{CO}_{2}$ in air.

To isolate oviduct APM (Smith \& Nothnick 1997), oviducts from early estrous mares were collected as for oviduct explant preparation. All further processing of the oviducts in the laboratory took place on ice $\left(0-4{ }^{\circ} \mathrm{C}\right)$. Upon arrival in the laboratory, oviducts were dissected free from surrounding tissue, opened longitudinally and rinsed with ice-cold saline. Subsequently, oviduct epithelia from the ampullary-isthmic mucosa was gently harvested by scraping and then suspended in hypotonic buffer solution (HiP; $50 \mathrm{mM}$ mannitol, $2 \mathrm{mM}$ Tris- $\mathrm{HCl}, \mathrm{pH}=7.1$ ). This suspension was homogenized by Turrax blending (IKA T-18 Ultra Turrax Digital Homogenizer; 115 VAC; Metrohm Belgium N.V., Antwerp, Belgium) at maximum speed for $2 \times 3 \mathrm{~min}$ and further sonicated for $5 \times 5 \mathrm{~s}$. To this homogenized suspension, $10 \mathrm{mM}$ solid $\mathrm{MgCl}_{2}$ (hexahydrate; Bornem, Belgium) was added, to crosslink non-apical cell plasma membranes. After incubation on a rotation plate for $30 \mathrm{~min}$, the suspension was centrifuged at $3000 \mathrm{~g}$ for $15 \mathrm{~min}$ to remove large cellular debris and agglutinated non-APMs. The pellet was discarded from the supernatant, and the supernatant was subsequently centrifuged at $27000 \boldsymbol{g}$ for $30 \mathrm{~min}$. After these centrifugation steps, the resulting pellet was resuspended in mannitol buffer (MB; $100 \mathrm{mM}$ mannitol, $20 \mathrm{mM}$ Tris-Hepes buffer, $\mathrm{pH}=7.4$ ) and homogenized by pipetting for $5 \mathrm{~min}$. In order to improve the degree of purity, unwanted debris was washed from the APM fraction using a $15 \mathrm{~min} 6000 \mathrm{~g}$ centrifugation step. The resulting pellet was discarded and the supernatant was centrifuged at $23000 \mathrm{~g}$ for $30 \mathrm{~min}$ to pellet the washed APM vesicles. Pelleted APM vesicles were then suspended in HBS supplemented with protease inhibitors and stored at $-80{ }^{\circ} \mathrm{C}$ until further use. Purity of the membrane isolates was assessed by measuring APM $\gamma$-glutamyl transpeptidase activity (Smith \& Nothnick 1997). Fractions of oviduct APM samples were collected, and protein content was determined using a modification of the method described by Lowry et al. (Flesch et al. 1998), using BSA as the standard.

\section{Semen collection and preparation}

Semen was collected using an artificial vagina (Colorado State University AV) from three adult stallions of proven fertility. The raw ejaculate was filtered through gauze to remove the gel fraction and any debris, before visual evaluation of sperm motility by light microscopy $(200 \times)$ on a heated stage at $37.0^{\circ} \mathrm{C}$. Semen with adequate sperm motility was immediately transported to the laboratory for further processing. The nuclei of spermatozoa in fresh semen with a concentration of $100-300 \times 10^{6}$ spermatozoa/ml were labelled by pre-incubating $1 \mathrm{ml}$ semen with $3.2 \mu \mathrm{M}$ Hoechst 33342 for $10 \mathrm{~min}$. Subsequently, the suspension of Hoechst-stained spermatozoa was washed using a 45/90\% Percoll gradient (Parrish et al. 1988, Tremoleda et al. 2003). Next, the sperm pellet was diluted in Whitten's medium $(100 \mathrm{mM} \mathrm{NaCl}, 4.7 \mathrm{mM} \mathrm{KCl}$, $1.2 \mathrm{mM} \mathrm{MgCl} 2,5.5 \mathrm{mM}$ glucose, $22 \mathrm{mM}$ HEPES, $2.4 \mathrm{mM}$ sodium lactate, $1.0 \mathrm{mM}$ pyruvate and $0.05 \%$ polyvinylpyrrolidone; $\mathrm{pH}=7.4$ and 280-300 $\mathrm{mOsm} / \mathrm{kg}$; adapted from McPartlin et al. (2008; further referred to non-capacitating medium) to the desired concentration (10, 20 or $50 \times 10^{6}$ spermatozoa $/ \mathrm{ml}$ ). At least three replicates of each experiment were performed using an ejaculate from each of the three stallions. The study was approved by the Ethical Committee of Ghent University's Faculty of Veterinary Medicine (EC2013/175 and EC2013/176).

\section{Sperm-oviduct explant and sperm-oviduct APM assay}

Oviduct explants were cultured in DMEM/F12 medium with $10 \%$ FBS, equilibrated with $5 \% \mathrm{CO}_{2}$ in a humidified atmosphere at $38.5{ }^{\circ} \mathrm{C}$, as described by Nelis et al. (2014). After overnight incubation, oviduct explant material contained vesicular epithelial cell clumps; vesicles with a diameter of $<200 \mu \mathrm{m}$ were selected, washed and transferred 
in groups of $5-45 \mu \mathrm{l}$ incubation droplets. Sperm binding to oviduct explants was performed in non-capacitating medium at $38.5{ }^{\circ} \mathrm{C}$ in air. To provide sperm capacitation supporting conditions, Whitten's medium was modified to capacitating medium by replacing the sodium lactate with $2.4 \mathrm{mM}$ calcium lactate and adding $25 \mathrm{mM} \mathrm{NaHCO}$ and $7 \mathrm{mg} / \mathrm{ml}$ BSA $(\mathrm{pH}=7.4$ and $280-300 \mathrm{mOsm} / \mathrm{kg}$; osmolality was adjusted by stepwise addition of $\mathrm{NaCl}$ ); this medium was pre-equilibrated for at least $2 \mathrm{~h}$ in a humidified atmosphere containing $5 \% \mathrm{CO}_{2}$ at $38.5{ }^{\circ} \mathrm{C}$ (adapted from McPartlin et al. (2008)). Elevated $\mathrm{pH}$ conditions were achieved by incubating capacitating medium in air until a pH of 7.9 was attained. In general, a final concentration of 2 million (carbohydrateglycosaminoglycan-D-penicillamine pre-incubation) or 5 million (lectin pre-incubation) Hoechst-stained spermatozoa per $\mathrm{ml}$ was produced by adding $5 \mu \mathrm{l}$ Percoll-washed and -diluted sperm (20 or $50 \times 10^{6}$ spermatozoa/ml) to the $45 \mu \mathrm{l}$ medium droplets containing the oviduct explants (Leemans et al. 2014). The $50 \mu \mathrm{l}$ medium droplets $\left(38.5{ }^{\circ} \mathrm{C}\right.$ in air) were covered under mineral oil to prevent evaporation. Similar experiments were repeated under capacitating conditions $\left(38.5{ }^{\circ} \mathrm{C}\right.$ in $5 \% \mathrm{CO}_{2}$ in air). Sperm-oviduct binding was additionally assessed in various non-capacitating conditions with individual or combined addition of BSA, calcium lactate, $\mathrm{NaHCO}_{3}$ or EGTA $(\mathrm{pH}=7.4$; media were preequilibrated for $2 \mathrm{~h}$ at $38.5{ }^{\circ} \mathrm{C}$ in $5 \% \mathrm{CO}_{2}$ in air to avoid a $\mathrm{pH}$ change in the medium). Sperm-oviduct binding was also tested in capacitating medium at $\mathrm{pH}$ 7.9. Identical conditions were used to test sperm release from oviduct explants, for which sperm-oviduct explants were previously established in non-capacitating conditions, subsequently washed twice and transferred to the sperm release conditions. Each replicate was performed using different ejaculates.

To establish a sperm-oviduct APM binding assay, a dot blot technique was adapted from Tsai et al. (2012). In brief, dot blotting was performed using the Easy-Titer ELIFA dot blot system (Pierce, Rockford, IL, USA). Nitrocellulose membranes (Sigma-Aldrich) were rinsed in Milli-Q, and oviduct APM samples containing $20 \mu \mathrm{g}$ proteins were subsequently pipetted ( $10 \mu \mathrm{l}$ of $2 \mu \mathrm{g} / \mu \mathrm{l}$ APM proteins) into separate wells. Membranes and adhering proteins were dried using a vacuum system (flow rate $100 \mu \mathrm{l} / 1.5 \mathrm{~min} /$ well). After blotting, non-specific binding was blocked using $50 \mathrm{ml} 10 \% \mathrm{BSA}$ in HBS for $1 \mathrm{~h}$ at room temperature. Oviduct APM-coated nitrocellulose membrane was subsequently washed twice with non-capacitating medium, and the spots were then individually cut. Per tested condition, three APM-coated blots were further co-incubated with carbohydrate and glycosaminoglycan pre-incubated, Hoechst-stained spermatozoa $\left(1 \times 10^{6}\right.$ spermatozoa/ml) under non-capacitating conditions $\left(38.5^{\circ} \mathrm{C}\right.$ ) in a $2 \mathrm{ml}$ Eppendorf tube (Sigma-Aldrich). Similar experiments were repeated under capacitating conditions $\left(38.5{ }^{\circ} \mathrm{C}\right.$ in $5 \% \mathrm{CO}_{2}$ in air). After 2-h co-incubation, APM-coated blots were washed three times. Quantitative analysis of dot blot labeling was performed by scanning the blots with a GS-700 densitometer (Bio-Rad Laboratories). Absorbance results achieved by the sperm-oviduct APM assay were corrected for the control absorbance (nitrocellulose membrane without coated oviduct APM).

\section{Effect of carbohydrate, glycosaminoglycan, D-penicillamine, lectin, $\mathrm{Ca}^{2+}, \mathrm{HCO}_{3}^{-}$and albumin pre-incubation on sperm-oviduct binding}

Before adding sperm to either oviduct explants or oviduct APM, Hoechst-stained spermatozoa were pre-incubated with various carbohydrates $(50 \mathrm{mM}$ : $\mathrm{D}(+)$-galactose, $\mathrm{N}$-acetylgalactosamine, $\mathrm{N}$-acetylglucosamine, $\mathrm{D}(+)$-fucose, $\mathrm{D}(+)$-mannose and $\mathrm{N}$-acetylneuraminic (sialic) acid; $5 \mathrm{mg} / \mathrm{ml}$ : asialofetuin, fetuin, fucoidan and mannan; $10 \mu \mathrm{g} / \mathrm{ml}$ : chondroitin sulfate, dextran sulfate, heparan sulfate, heparin, hyaluronic acid and keratan sulfate) or D-penicillamine $(0.125,0.25,0.5,1,5$ and $10 \mathrm{mM}$; D-penicillamine stock solution was prepared max $10 \mathrm{~min}$ before the start of sperm pre-incubation experiments). Hoechst-stained sperm were pre-incubated at a concentration of 10 or $20 \times 10^{6}$ spermatozoa $/ \mathrm{ml}$ in $500 \mu$ l non-capacitating and capacitating conditions at $38.5{ }^{\circ} \mathrm{C}$ to saturate sperm plasma membrane receptors so that they could have a competitive inhibitory effect on sperm-oviduct binding. After $20 \mathrm{~min}$, sperm suspensions were washed by centrifugation $(600 \mathrm{~g}$; $5 \mathrm{~min})$ with $500 \mu \mathrm{l}$ non-capacitating or capacitating medium, and $5 \mu \mathrm{l}$ of the washed sperm solution was added to either oviduct explants $\left(2 \times 10^{6}\right.$ spermatozoa $\left./ \mathrm{ml}\right)$ or oviduct APM $\left(1 \times 10^{6}\right.$ spermatozoa $\left./ \mathrm{ml}\right)$ (control condition). The competitive inhibitory effect of lectins on sperm-oviduct binding was assessed by pretreating oviduct explants with individual, or mixtures of, various lectins $(50 \mu \mathrm{g} / \mathrm{ml}$ : PNA, DBA, HPA, WGA, UEA 1I, SNA, Con A, LCA, PSA or in case of the lectin mix; $20 \mu \mathrm{g} / \mathrm{ml}$ of each lectin; table in supplementary information, see section on supplementary data given at the end of this article) in $50 \mu$ droplets of non-capacitating medium under mineral oil at $38.5{ }^{\circ} \mathrm{C}$. After $2 \mathrm{~h}$, oviduct explants were washed in non-capacitating medium, and $5 \mu \mathrm{l}$ Hoechst-stained sperm was added to the $45 \mu \mathrm{l}$ oviduct explant containing non-capacitating droplets $\left(5 \times 10^{6}\right.$ spermatozoa $\left./ \mathrm{ml}\right)$. These incubations were repeated using capacitating conditions in which Hoechst-stained spermatozoa were pre-incubated in either full capacitation medium, individual or combinations of $7 \mathrm{mg} / \mathrm{ml} \mathrm{BSA}, 2.4 \mathrm{mM}$ calcium lactate or $25 \mathrm{mM} \mathrm{NaHCO}_{3}$ in non-capacitating medium $(\mathrm{pH}=7.4 ; 2 \mathrm{~h}$ pre-equilibrated in $5 \% \mathrm{CO}_{2}$ in air to avoid a $\mathrm{pH}$ change in the medium). To test the role of $\mathrm{Ca}^{2+}$ in sperm-oviduct binding, 2 (non-capacitating medium) or $4 \mathrm{mM}$ (capacitating medium) EGTA (Sorensen et al. 1999, Loux et al. 2013) was added ( $\mathrm{pH}=7.4 ; 2 \mathrm{~h}$ pre-equilibrated in $5 \% \mathrm{CO}_{2}$ in air to avoid a $\mathrm{pH}$ change in the medium). In addition, the effect of elevated $\mathrm{pH} 7.9$ in capacitating medium was assessed. Similar incubation conditions were used to test the ability of the capacitating factors to trigger sperm-oviduct release after establishment of sperm-oviduct complexes in non-capacitating medium. Moreover, the effect of sperm concentration (range 1-100 $\times$ $10^{6} \mathrm{spermatozoa} / \mathrm{ml}$ ) on binding capacity of pre-incubated sperm to oviduct explants was assessed in non-capacitating, capacitating and combined albumin and $\mathrm{HCO}_{3}^{-}$-enriched noncapacitating conditions. Ultimately, sperm in both control noncapacitating medium and in combined albumin and $\mathrm{HCO}_{3}^{-}$enriched non-capacitating medium were exposed to oviduct explants at the same concentration of non-agglutinated sperm $\left(2 \times 10^{6}\right.$ spermatozoa $\left./ \mathrm{ml}\right)$. Each replicate was performed using different ejaculates. 


\section{Individual and combined effect of $\mathrm{Ca}^{2+}, \mathrm{HCO}_{3}^{-}$ or albumin on head-to-head agglutination of stallion spermatozoa}

Head-to-head sperm agglutination was assessed after 0.5 and $2 \mathrm{~h}$ in non-capacitating medium containing $7 \mathrm{mg} / \mathrm{ml}$ BSA, $2.4 \mathrm{mM}$ calcium lactate or $25 \mathrm{mM} \mathrm{NaHCO}$ individually or in combinations. To test the role of $\mathrm{Ca}^{2+}$ in sperm-oviduct binding, 2 (non-capacitating medium) or $4 \mathrm{mM}$ (capacitating medium) EGTA (Sorensen et al. 1999, Loux et al. 2013) was added $\left(\mathrm{pH}=7.4 ; 2 \mathrm{~h}\right.$ pre-equilibrated in $5 \% \mathrm{CO}_{2}$ in air to avoid a $\mathrm{pH}$ change in the medium). The effect of elevated $\mathrm{pH}$ (7.9) in capacitating medium was also assessed. Sperm was incubated at a concentration of $10 \times 10^{6}$ spermatozoa $/ \mathrm{ml}$ in $500 \mu \mathrm{l}$ of each medium sample at $38.5{ }^{\circ} \mathrm{C}$. After 0.5 - and 2-h incubation, sperm suspensions were evaluated for sperm agglutination by placing a $10 \mu \mathrm{l}$ aliquot onto a pre-warmed glass slide covered with a warm glass cover slip. For each medium sample, 200 randomly selected motile spermatozoa were examined, and subsequently, the percentage of head-to-head agglutinated sperm was calculated.

\section{Effect of N-glycosidase F (PNGase) treatment on sperm-oviduct binding}

To elucidate the involvement of $N$-linked carbohydrates in sperm-oviduct interaction, oviduct explants and oviduct APM were treated for $2400 \mathrm{~h}$ with and without (control) the $\mathrm{N}$-glycosidase $\mathrm{F}$ enzyme (Takasaki et al. 1982, Tarentino \& Plummer 1987). To this end, ten oviduct explants or $20 \mu \mathrm{g}$ oviduct APM proteins were incubated in DPBS to which $3 \mu \mathrm{l}$ $\mathrm{N}$-glycosidase $\mathrm{F}$ was then added. Enzyme activity was evaluated by Con A-FITC staining of oviduct explants before and after $\mathrm{N}$-glycosidase $\mathrm{F}$ treatment (Desantis et al. 2004). The enzyme-treated oviduct explants and oviduct APM were further processed for sperm binding assays as previously described. Incubations were performed under non-capacitating and capacitating conditions.

\section{Carbohydrate expression on oviduct explant epithelial cells}

To examine which carbohydrates could play a key role in sperm-oviduct binding, the expression of carbohydrate moieties on the oviduct epithelial explants was assessed using fluorescein (FITC)-conjugated lectins (PNA, DBA, HPA, WGA, UEA 1, SNA, Con A, LCA and PSA). Specificity of the lectins was previously demonstrated by Desantis et al. (2004, 2005). Briefly, after fixing in 4\% (w/v) paraformaldehyde in DPBS for $15 \mathrm{~min}$ at room temperature, oviduct explants were washed twice in $500 \mu \mathrm{l}$ blocking buffer (DPBS containing 1\% BSA) and stained with $50 \mu \mathrm{g} / \mathrm{ml}$ FITC-conjugated lectins in DPBS (Desantis et al. 2004, 2005) for $15 \mathrm{~min}$ at room temperature. After two washes with DPBS, the stained oviduct explants were mounted as described above using 1.4-diazabicyclo (2.2.2) octane (DABCO) as antifade. Samples were examined using a Leica DMR microscope (Brussel, Belgium) equipped with a mercury lamp and appropriate filters, at $400 \times$ magnification. Quantification of carbohydrate expression was performed by scoring the fluorescence intensity $(+++,++,+$ and -$)$. Imaging of the lectin-stained oviduct explants was performed using standard settings (camera exposure: $204.1 \mathrm{~ms}$; camera capture format: $2560 \times 1920)$.

\section{Tail-associated protein tyrosine phosphorylation after exposure to various sulfated glycosaminoglycans}

After 6-h incubation, the same glycosaminoglycan conditions were used as during the pre-incubation steps to assess competitive inhibition of sperm-oviduct binding. A portion of the treated Hoechst-stained sperm suspensions $\left(10 \times 10^{6}\right.$ spermatozoa $/ \mathrm{ml}$ ) were further processed to detect protein tyrosine phosphorylation, as previously described (Leemans et al. 2014). In brief, spermatozoa were washed twice in $1 \mathrm{ml}$ DPBS (600 g; $5 \mathrm{~min}$ ) and fixed in $500 \mu \mathrm{l} \%$ paraformaldehyde in DPBS at room temperature for $15 \mathrm{~min}$. The fixative was removed by three washing steps using $1 \mathrm{ml}$ DPBS $(600 \mathrm{~g}$; $5 \mathrm{~min})$. The washed spermatozoa were subsequently incubated in $500 \mu \mathrm{l} 0.1 \%$ Triton $\mathrm{X}-100$ in DPBS for $10 \mathrm{~min}$ at room temperature to ensure complete membrane permeabilization. The immobilized and permeabilized spermatozoa were then washed twice $(600 \mathrm{~g}$; $5 \mathrm{~min})$ in $1 \mathrm{ml}$ DPBS and further incubated in $500 \mu \mathrm{l}$ blocking buffer (DPBS containing $1 \%$ BSA) for $10 \mathrm{~min}$ at room temperature. Next, spermatozoa were incubated in $200 \mu \mathrm{l}$ buffer containing $0.1 \%$ BSA and supplemented with a mouse monoclonal 4G10 Platinum IgG (Millipore) protein anti-phosphotyrosine antibody (diluted 1:500) at $4{ }^{\circ} \mathrm{C}$. After overnight incubation, unbound antibody was removed by washing the spermatozoa twice using $1 \mathrm{ml}$ of DPBS containing $0.1 \%$ BSA $(600 \mathrm{~g} ; 5 \mathrm{~min})$. The resulting spermatozoa were then stained with a monoclonal goat antimouse antibody conjugated to Alexa Fluor 488 (Invitrogen) for $1 \mathrm{~h}$ at room temperature. After immunolabeling, the nonbound antibody conjugates were removed by washing three times using $1 \mathrm{ml}$ DPBS containing $0.1 \%$ BSA (600 g; $5 \mathrm{~min}$ ) and once using DPBS. The immunolabeled spermatozoa were mounted on glass slides as described above and sealed with nail polish. The proportion of the total sperm population with green fluorescent tails (and Hoechst 33342 fluorescent heads) was determined by randomly assessing 200 spermatozoa. Samples were examined using a Leica DMR microscope equipped with a mercury lamp and appropriate filters, at $400 \times$ magnification.

\section{Quantification of sperm-oviduct binding and tail-associated protein tyrosine phosphorylation}

Density of sperm binding to oviduct APM after 2-h co-incubation was determined after two washing steps, in either noncapacitating or capacitating medium, by quantitative analysis of dot blot labeling. This analysis was performed by scanning the blots with a GS-700 densitometer equipped with a UV lamp (Bio-Rad Laboratories) using Quantity One acquisition software (version 4.3, Bio-Rad). Densitometric quantitation was carried out using the Gel-Pro Analyzer Software (version 3.0; Media Cybernetics, Silver Spring, MD, USA).

Density of sperm binding to the oviduct explants after 2-h co-incubation was similarly determined in five microscopic 
fields (400 $\times$ magnification), after two washing steps. The percentage of spermatozoa with tail-associated protein tyrosine phosphorylation ( $\mathrm{PY}+/$ Hoechst + ) was determined by evaluating 200 randomly selected spermatozoa (Hoechst + ). Both parameters were evaluated by means of fluorescence microscopy using a Leica DMR microscope equipped with excitation filters BP $340 / 380 \mathrm{~nm}$, BP 450/490 nm, BP $560 / 40 \mathrm{~nm}$ and a $100 \mathrm{~W}$ mercury lamp. Alexa Fluor 488-conjugated goat anti-mouse antibody and Hoechst 33342 were sequentially excited using 499 and $345 \mathrm{~nm}$ wavelengths. Emission spectra of the dyes were then filtered at 519 and $478 \mathrm{~nm}$. These emission spectra were detected by blue (LP $425 \mathrm{~nm}$ ), green (LP $515 \mathrm{~nm}$ ) and red (BP 645/75 nm) filters, corresponding to the emission peaks of the dyes. Images were acquired using the Image Database program (Leica, Van Hopplynus N.V., Brussel, Belgium). In addition, the surface area of the oviduct explants in each microscopic field (at $400 \times$ magnification) was measured using this program. The two fluorophores were checked for signal overlap, and no leakage of signals was detected.

Head-to-head sperm agglutination after 0.5 and $2 \mathrm{~h}$ in various medium conditions was determined by evaluating 200 randomly chosen, motile spermatozoa and observed at $400 \times$ magnification using the DIC and warm stage $\left(38.5{ }^{\circ} \mathrm{C}\right)$ equipped Leica DM 5500 B fluorescence microscope, as described above.

\section{Statistical analysis}

Competitive carbohydrate/glycosaminoglycans/lectin/D-penicillamine/ $\mathrm{N}$-glycosidase $\mathrm{F}$ inhibition of sperm-oviduct binding, the effect of various glycosaminoglycans on protein tyrosine phosphorylation and the effect of various capacitating factors (individual and combined effects of $\mathrm{Ca}^{2+}, \mathrm{HCO}_{3}^{-}$or albumin) on sperm-oviduct binding, release and head-to-head agglutination were assessed by ANOVA. Significant differences in the number of oviduct-bound spermatozoa, or optical spot density, and the percentage of tyrosine phosphorylated $(\mathrm{PY}+)$ and head-to-head agglutinated spermatozoa over time were determined using repeated measures ANOVA with Greenhouse-Geisser and Bonferroni correction, as implemented in the general linear model. Scheffé post hoc tests were performed for pairwise comparisons. Statistical analysis and graph plotting was performed using SPSS version 20 for Windows (SPSS IBM). Differences were considered significant if $P<0.05$.

\section{Results}

\section{Standardization of sperm-oviduct explant and sperm-oviduct APM assays}

We previously showed that the saturation concentration for sperm binding to oviduct explants in non-capacitating conditions was reached at $5 \times 10^{6}$ spermatozoa $/ \mathrm{ml}$ (Leemans et al. 2014). To test the ability of carbohydrates to competitively inhibit sperm-oviduct explant binding, a sperm concentration of $2 \times 10^{6}$ spermatozoa $/ \mathrm{ml}$ was used. A similar experiment was performed for the sperm-oviduct APM assay, and sperm binding to oviduct APM was saturated at $2 \times 10^{6}$ spermatozoa $/ \mathrm{ml}$. Therefore, a below saturation concentration of $1 \times$ $10^{6}$ spermatozoa $/ \mathrm{ml}$ was used to test competitive carbohydrate inhibition of sperm-oviduct binding (Fig. 1). To test competitive lectin inhibition of spermoviduct explant binding, a concentration above the saturation level was used $\left(5 \times 10^{6}\right.$ spermatozoa $\left./ \mathrm{ml}\right)$.

To standardize the sperm-oviduct APM assay, the purity of the APM fractions was checked using wellestablished enzyme assays (Smith \& Nothnick (1997) for full validation). $\gamma$-glutamyl transpeptidase was used as a marker for the APM and proved to be enriched $21 \pm 4$ times in plasma membrane preparations $(n=3)$.

\section{Tested carbohydrates did not competitively reduce sperm-oviduct APM binding}

As demonstrated by Suarez (2001, 2008b), speciesspecific carbohydrate moieties expressed on the epithelium facilitated binding of the head of the spermatozoa that ultimately populate the sperm reservoir. In order to assess the importance of carbohydrates in sperm-oviduct binding in equids, we used our oviduct-derived APM to test competitive carbohydrate inhibition of sperm binding. Sperm binding to nitrocellulose coated with oviductal APM was assessed after pre-incubating spermatozoa with carbohydrates (D-galactose, $\mathrm{N}$-acetylgalactosamine, $\mathrm{N}$-acetylglucosamine, asialofetuin, fetuin, D-fucose, fucoidan, D-mannose, mannan and $\mathrm{N}$-acetylneuraminic (sialic) acid). None of the tested carbohydrates reduced the sperm-oviduct APM binding density in either

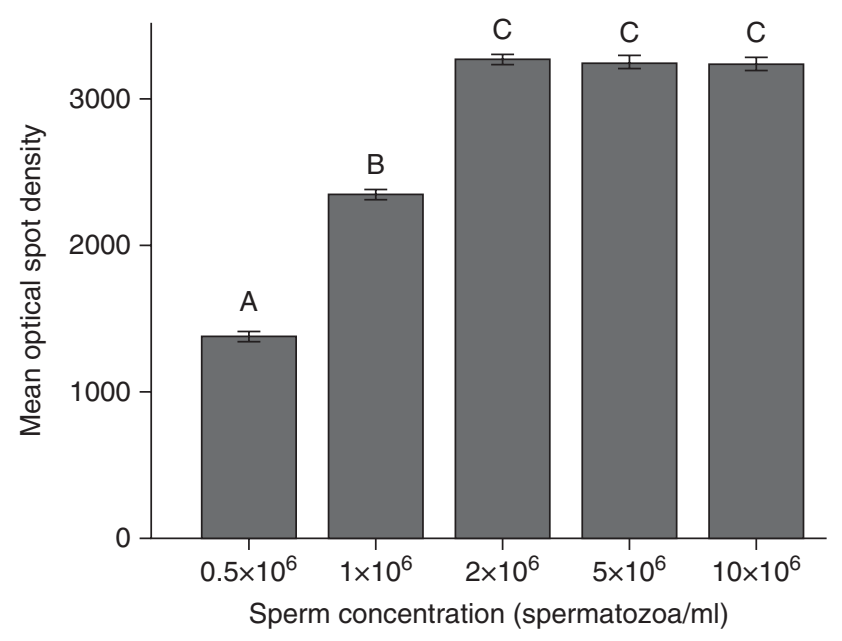

Figure 1 Effect of sperm concentration on binding density of stallion sperm to equine oviduct APM under non-capacitating conditions. Saturation of sperm-oviduct explant binding was observed at $2 \times 10^{6}$ spermatozoa $/ \mathrm{ml}$. Data represent mean ( \pm s.D.) optical spot density ( $n=30 /$ group) in three replicates. Values that differ significantly are indicated by different capitals. One-way ANOVA, followed by Bonferroni post hoc tests for pairwise comparison. 


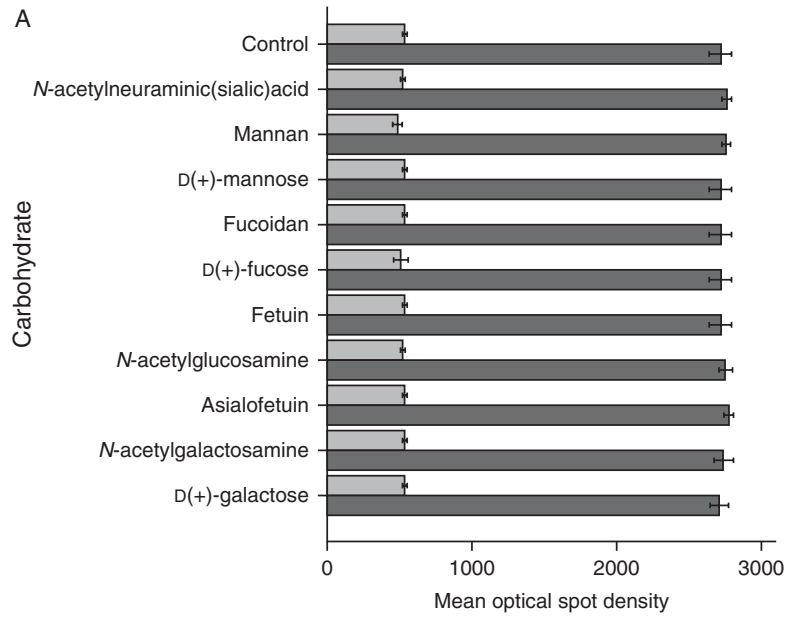

B

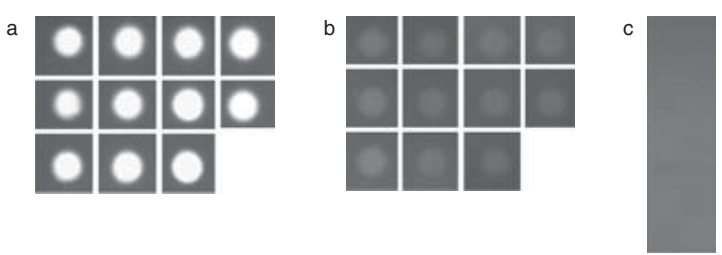

Figure 2 (A) Effect of different carbohydrates (D-galactose,

$\mathrm{N}$-acetylgalactosamine, $\mathrm{N}$-acetylglucosamine, asialofetuin, fetuin, D-fucose, fucoidan, D-mannose, mannan and $\mathrm{N}$-acetylneuraminic (sialic) acid) on equine sperm-oviduct APM binding density under non-capacitating (dark grey bars) and capacitating (light grey bars) conditions. Data represent mean ( \pm s.D.) optical spot density ( $n=10$ /group) over three replicates. Repeated measure ANOVA with Greenhouse-Geisser and Bonferroni correction, followed by Scheffé post hoc tests for pairwise comparisons. (B) Fluorescent spots represent Hoechst-stained spermatozoa bound to oviduct APM coated on nitrocellulose after pre-incubation with the test carbohydrate followed by $2 \mathrm{~h}$ co-incubation in (a) non-capacitating and (b) capacitating medium. Each spot represents one tested carbohydrate (row 1-3 from left to right: D-galactose, $\mathrm{N}$-acetylgalactosamine, asialofetuin, $\mathrm{N}$-acetylglucosamine, fetuin, D-fucose, fucoidan, D-mannose, mannan, $\mathrm{N}$-acetylneuraminic (sialic) acid and controls (row 3)). (c) Nitrocellulose paper without oviduct APM was included as an additional control and the optical density of the paper subtracted from the optical spot density of the other spots (a, b, c: original magnification).

non-capacitating ( $P>0.95$ for all comparisons) or capacitating conditions ( $P>0.22$ for all comparisons). Similar to our previous study (Leemans et al. 2014), sperm-oviduct binding density was significantly higher in non-capacitating than capacitating conditions $(P<0.001$ for all comparisons; Fig. 2A and B).

\section{Tested carbohydrates did not reduce sperm-oviduct explant binding}

To validate the results obtained for the oviduct-derived APM model (described above), the same experiments were carried out using oviduct explants. In accordance with the oviduct APM experiments, none of the tested carbohydrates reduced the density of sperm binding to oviduct explants in either non-capacitating $(P>0.96$ for all comparisons) or capacitating conditions ( $P>0.59$ for all comparisons). As for APM, sperm-oviduct binding density was significantly higher in non-capacitating than capacitating conditions $(P<0.001$ for all comparisons; Fig. $3 \mathrm{~A}$ and $\mathrm{B})$.

\section{$\mathrm{N}$-acetylgalactosamine and $D$-mannose/D-glucose moieties are expressed on equine oviduct explant epithelium}

Lectin histochemistry of oviductal epithelium was used to demonstrate that $\mathrm{N}$-acetylgalactosamine (DBA and $\mathrm{HPA}+++$ ), $\mathrm{N}$-acetylneuraminic (sialic) acid (SNA +++ ) and D-mannose/D-glucose (Con A, LCA and PSA +++ ) were the pre-dominant

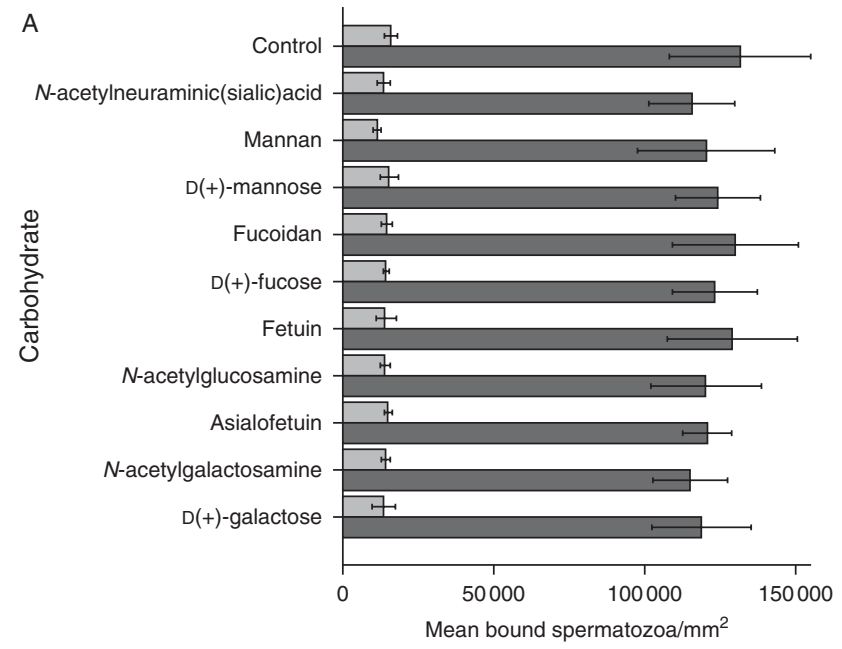

B

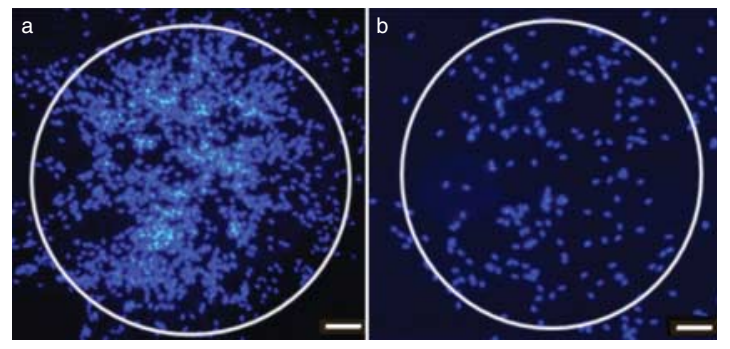

Figure 3 (A) Effect of different carbohydrates (D-galactose,

$\mathrm{N}$-acetylgalactosamine, asialofetuin, $\mathrm{N}$-acetylglucosamine, fetuin, D-fucose, fucoidan, D-mannose, mannan and $\mathrm{N}$-acetylneuraminic (sialic) acid) on equine sperm-oviduct explant binding density under non-capacitating (dark grey bars) and capacitating (light grey bars) conditions. Data represent mean ( \pm s.D.) number of spermatozoa bound to oviduct explants ( $n=10$ /group) over five replicates. Repeated measure ANOVA with Greenhouse-Geisser and Bonferroni correction, followed by Scheffé post hoc tests for pairwise comparison.

(B) Fluorescence micrographs represent Hoechst-stained spermatozoa bound to oviduct explants after 2-h co-incubation in (a) noncapacitating and (b) capacitating medium (b, c: original magnification, $400 \times$, scale bar $=25 \mu \mathrm{m})$. 

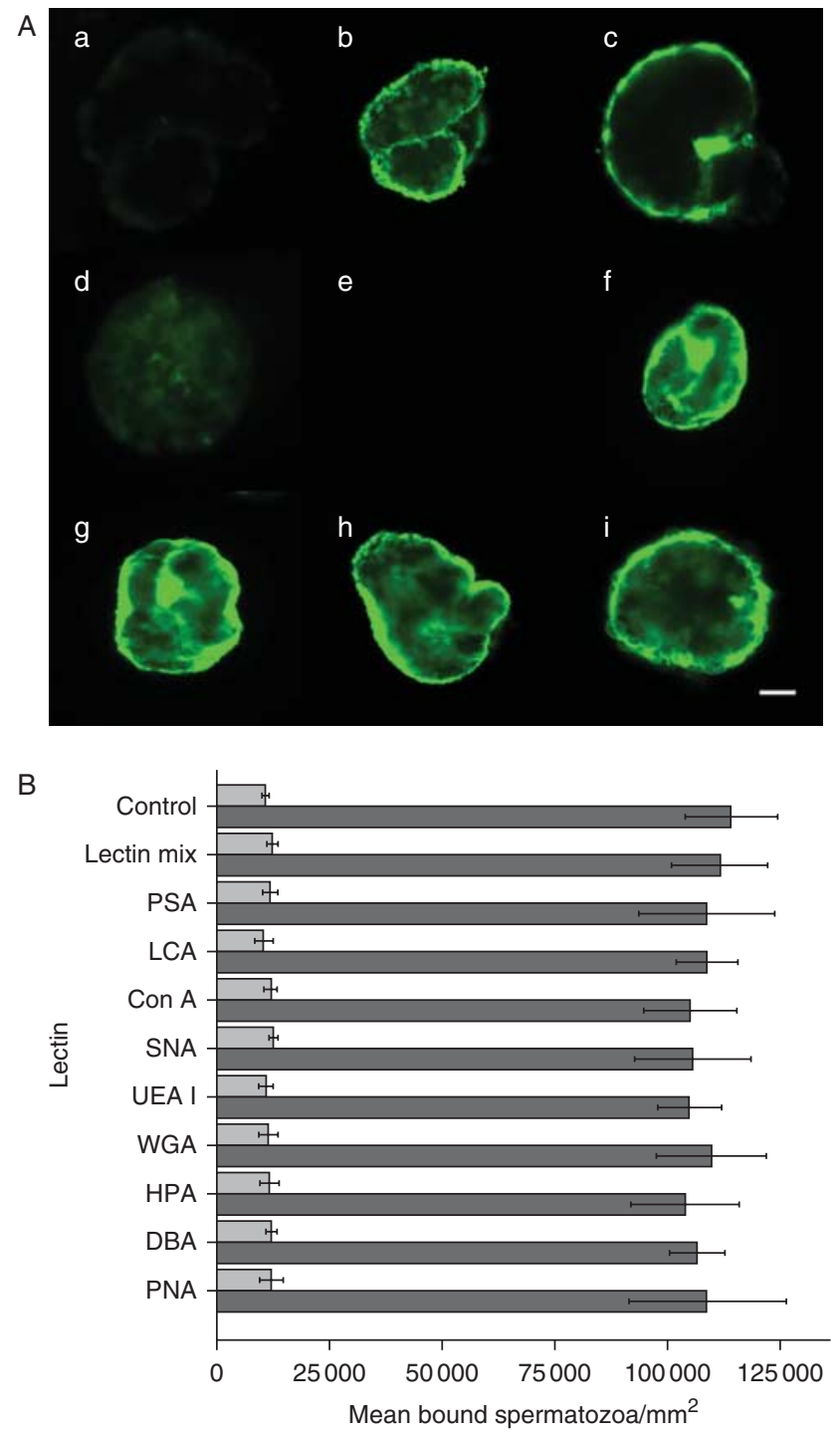

Figure 4 (A) Fluorescence micrographs of carbohydrate expression patterns on equine oviduct explant epithelia. Carbohydrate expression was assessed using various FITC-conjugated lectins: (a) PNA +/-, (b) $\mathrm{DBA}+++$, (c) $\mathrm{HPA}+++$, (d) WGA + , (e) UEA I - , (f) $\mathrm{SNA}+++$, (g) Con A +++ , (h) LCA +++ and (i) PSA $+++(a, b, c, d, e, f, g$, h, i: original magnification, $400 \times$, scale bar $=25 \mu \mathrm{m}$ ). (B) Effect of an individual or the mix of different lectins (PNA, DBA, HPA, WGA, UEA I, Con A, LCA, PSA and SNA) on sperm-oviduct explant binding density under non-capacitating (dark grey bars) and capacitating (light grey bars) conditions. Data represent mean ( \pm s.D.) number of spermatozoa bound to oviduct explants ( $n=10 /$ group) over three replicates. Repeated measure ANOVA with Greenhouse-Geisser and Bonferroni correction, followed by Scheffé post hoc tests for pairwise comparison.

carbohydrate moieties expressed on equine oviduct epithelium. WGA-FITC $(+)$, a lectin that binds to $\mathrm{N}$-acetylglucosamine moieties and to a lesser extent $\mathrm{N}$-acetylneuraminic (sialic) acid, displayed a weaker expression pattern probably because of the expression of the latter carbohydrate. D-galactose (PNA) and L-fucose moieties were not detected on equine oviduct epithelium (UEA 1) (Fig. 4A).

\section{Tested lectins did not reduce sperm-oviduct explant binding}

Various lectins were also tested in the sperm-oviduct assays to alternatively examine the role of oviduct carbohydrate moieties in sperm-oviduct binding. Sperm binding to oviduct explants was examined after pre-incubating oviduct explants with individual or a mix of lectins (PNA, DBA, HPA, WGA, UEA I, SNA, Con A, LCA and PSA) and compared to control explants not exposed to lectins. Similar to the carbohydrate studies, none of the lectins reduced the sperm binding density to oviduct explants in either non-capacitating ( $P>0.99$ for all comparisons) or capacitating conditions $(P>0.96$ for all comparisons; Fig. 4B); again, spermoviduct binding density was significantly higher in non-capacitating compared to capacitating conditions $(P<0.001$ for all comparisons).

\section{$\mathrm{N}$-linked carbohydrates do not regulate sperm-oviduct binding}

$\mathrm{N}$-linked glycosylation is prevalent in proteins destined for extracellular locations including proteins expressed on the extracellular side of the plasma membrane, secreted proteins and proteins present in body fluids (Roth 2002, Zhang et al. 2003). The possible involvement of $\mathrm{N}$-glycosylated moieties in sperm-oviduct binding was tested by pretreating either oviduct APM

A

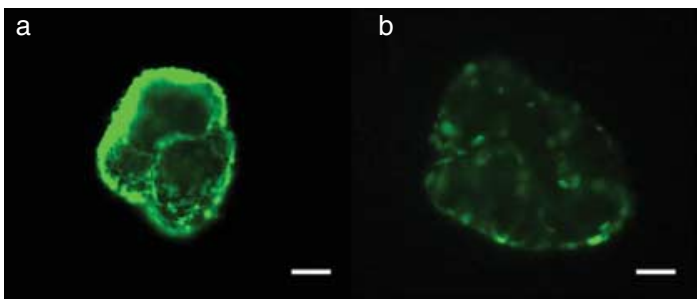

B
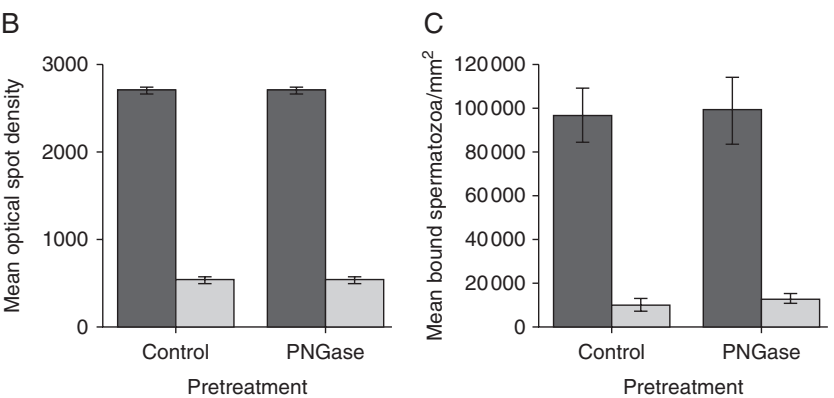

Figure 5 (A) Fluorescence micrographs of Con A-FITC-stained equine oviduct explants (a) before and (b) after PNGase treatment ( $a, b$ : original magnification, $400 \times$, bar $=25 \mu \mathrm{m}$ ). The effect of PNGase pretreatment on (B) sperm-oviduct APM and (C) sperm-oviduct explant binding density under non-capacitating (dark grey bars) and capacitating (light grey bars) conditions was also assessed. Data represent mean optical spot densities ( $n=3$ spots/group) and mean ( \pm s.D.) number of spermatozoa bound to oviduct explants ( $n=10$ /group) over three replicates. Repeated measure ANOVA with Greenhouse-Geisser and Bonferroni correction, followed by Scheffé post hoc tests for pairwise comparison. 
or oviduct explants for $2400 \mathrm{~h}$ with the enzyme $\mathrm{N}$-glycosidase $\mathrm{F}$ (PNGase), which removes $\mathrm{N}$-linked glycosylated moieties from glycoproteins. Indeed, the enzyme treatment effectively removed Con A binding sites, given that Con A-FITC staining was markedly reduced after $\mathrm{N}$-glycosidase $\mathrm{F}$ treatment (Fig. 5A). However, the $\mathrm{N}$-glycosidase $\mathrm{F}$ pretreatment of oviduct epithelium did not significantly affect sperm-oviduct binding densities in either the oviduct APM (Fig. 5B) or oviduct explant systems (Fig. 5C), and in either non-capacitating (APM assay: $P>0.75$ for all comparisons; oviduct explant assay:

A

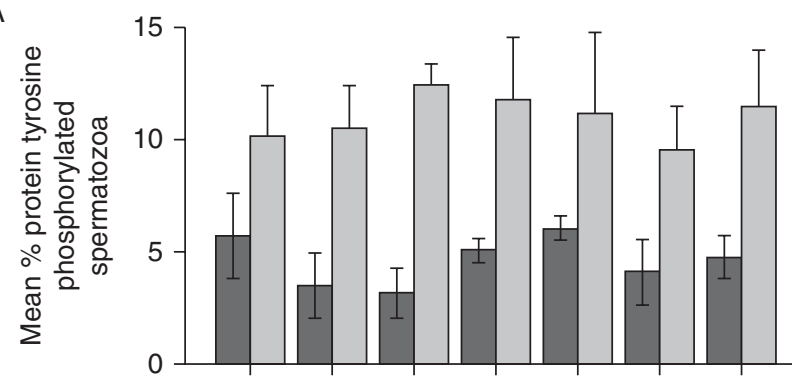

$\mathrm{B}$
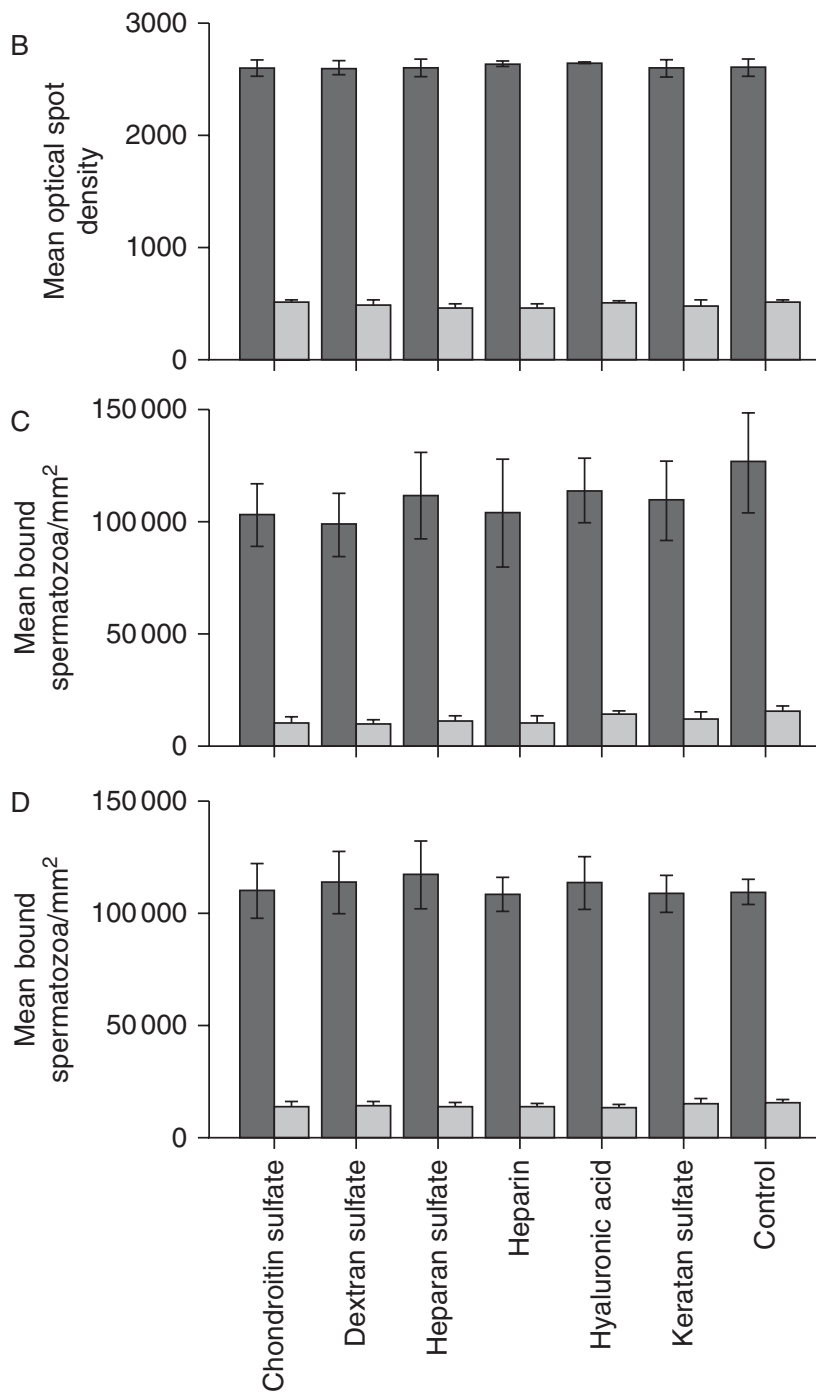

$P>0.09$ for all comparisons) or capacitating conditions (APM assay: $P>0.95$ for all comparisons; oviduct explant assay: $P>0.17$ for all comparisons).

\section{In vitro capacitation induces protein tyrosine phosphorylation in equine sperm tails whereas glycosaminoglycans have no effect}

In cattle, heparin-like sulfated glycosaminoglycans, normally present in follicular and oviductal fluid, have been proposed to be potential in vivo capacitation agents (Parrish et al. 1988, 1989a,b). Heparin also initiated sperm release from the bovine oviduct epithelium (Talevi \& Gualtieri 2001), associated with protein tyrosine phosphorylation (Gualtieri et al. 2005). Interestingly, in the mare, high concentrations of sulfated glycosaminoglycans have been reported in follicular and oviductal fluid (Varner et al. 1991). Therefore, the in vitro effect of added (sulfated) glycosaminoglycans on protein tyrosine phosphorylation (as a marker for sperm capacitation) was monitored. None of the tested glycosaminoglycans had any stimulatory or inhibitory effect on tailassociated protein tyrosine phosphorylation of spermatozoa in suspension after 6 -h incubation in non-capacitating conditions $(8 \pm 4 \% ; P>0.09$ for all comparison; Fig. 6A). Moreover, the increase in tyrosine-phosphorylated sperm $(P<0.001$ for all comparisons) induced by capacitating conditions ( $15 \pm 7 \%$; Fig. 6A) was not affected by addition of glycosaminoglycans ( $P>0.79$ for all comparisons). These results indicate that glycosaminoglycans do not induce equine sperm capacitation.

\section{Glycosaminoglycans do not competitively inhibit sperm-oviduct explant binding}

In cattle, after contact with various capacitation inducers (e.g. glycosaminoglycans and $\mathrm{HCO}_{3}^{-}$), the affinity of

Figure 6 (A) Effect of different glycosaminoglycans on protein tyrosine phosphorylation in the tail of stallion sperm incubated in noncapacitating and capacitating media for $6 \mathrm{~h}$. No effect of added glycosaminoglycans on protein tyrosine phosphorylation was observed in either condition. Data represent mean ( \pm s.D.) percentages of protein tyrosine-phosphorylated spermatozoa in non-capacitating (light grey bars) and capacitating media (dark grey bars) $(n=200$ spermatozoa in each group; three replicates). Repeated measure ANOVA with Greenhouse-Geisser and Bonferroni correction, followed by Scheffé post hoc tests for pairwise comparison. The effect of different glycosaminoglycans (chondroitin sulfate, dextran sulfate, heparan sulfate, heparin, hyaluronic acid and keratan sulfate) on (B) sperm-oviduct APM, (C) sperm-oviduct explant binding density and (D) sperm release from oviduct explants under non-capacitating (dark grey bars) and capacitating (light grey bars) conditions was assessed. Data represent mean ( \pm s.D.) number of spermatozoa bound to oviduct explants ( $n=10$ /group) over five replicates. Repeated measure ANOVA with Greenhouse-Geisser and Bonferroni correction, followed by Scheffé post hoc tests for pairwise comparison. 
non-capacitated spermatozoa for carbohydrate moieties on the oviduct epithelium decreases dramatically, while the affinity for zona pellucida glycoproteins rises (Sostaric et al. 2005). Initially, competition for oviduct carbohydrate binding receptors plays a role in sperm release from oviduct epithelium, while capacitation induces membrane changes that further modify the affinity of sperm receptors. We assessed the ability of spermatozoa to bind to oviduct APM or oviduct explants during a 2-h co-incubation after pretreatment with various sulfated glycosaminoglycans (chondroitin sulfate, dextran sulfate, heparan sulfate, heparin, hyaluronic acid and keratan sulfate). None of the tested glycosaminoglycans decreased the sperm-oviduct binding density in either non-capacitating (APM assay: $P>0.93$ for all comparisons; Fig. 6B; oviduct explant assay: $P>0.20$ for all comparisons; Fig. 6C) or capacitating conditions (APM assay: $P>0.49$ for all comparisons; Fig. 6B; oviduct explant assay: $P>0.09$ for all comparisons; Fig. 6C). Similar to other experiments, only capacitating conditions decreased the density of sperm-oviduct epithelium binding (APM and oviduct explant assays: $P<0.001$ for all comparisons).

\section{D-penicillamine does not reduce sperm-oviduct explant binding density}

In cattle, disulfide reductants like D-penicillamine markedly reduce the affinity of spermatozoa for carbohydrate moieties on the oviduct epithelium (Gualtieri et al. 2009). Moreover, release of bull spermatozoa from oviduct epithelium following exposure to D-penicillamine was provoked by redox control of sperm surface protein sulfhydryls (S-S↔2SH). We assessed the ability of spermatozoa to bind to oviduct explants after pretreatment with various concentrations of D-penicillamine $(0,0.125,0.25,0.5,1,5$ and $10 \mathrm{mM})$, none of which reduced oviduct membrane binding density in either non-capacitating ( $P>0.93$ for all comparisons) or capacitating ( $P>0.81$ for all comparisons) conditions. Similar to other experiments, only capacitating conditions decrease the density of sperm-oviduct epithelium binding ( $P<0.001$ for all comparisons; Fig. 7A).

\section{Sperm-oviduct binding is not regulated by $\mathrm{Ca}^{2+}$, but a combination of albumin and $\mathrm{HCO}_{3}^{-}$reduces sperm-oviduct explant binding density}

As shown in previous experiments, capacitating conditions supported sperm-oviduct binding at a significantly lower level than non-capacitating conditions. In cattle, $\mathrm{Ca}^{2+}$-dependent lectin binding has been shown to initiate sperm-oviduct binding, whereas $\mathrm{HCO}_{3}^{-}$ decreased sperm-oviduct affinity (Sostaric et al. 2005). We, therefore, tested the effect of pre-incubation for 20 min with each of the three major factors required for capacitation in vitro (albumin and/or $\mathrm{Ca}^{2+}$ and/or
$\mathrm{HCO}_{3}^{-}$), individually or in combinations, on the ability of spermatozoa to bind to oviduct explants during a subsequent 2-h co-incubation. The results indicated that binding of stallion spermatozoa to oviduct explant epithelium was independent of $\mathrm{Ca}^{2+}$ and alkalinity $\left(\mathrm{pH}\right.$ 7.9). However, sperm pre-incubated in $\mathrm{HCO}_{3}^{-}$- and albumin-enriched media showed a significantly decreased binding density for the oviduct in all groups $(P<0.001$; Fig. 8A) while individual exposure to either $\mathrm{HCO}_{3}^{-}$or albumin had no effect. Sperm-oviduct binding density was also significantly lower when $2 \mathrm{mM}$ EGTA was added to non-capacitating medium $(P<0.001)$. Despite the latter finding, we conclude that equine sperm-oviduct binding is $\mathrm{Ca}^{2+}$ independent because levels of sperm-oviduct binding were still very high in $\mathrm{Ca}^{2+}$-free conditions.
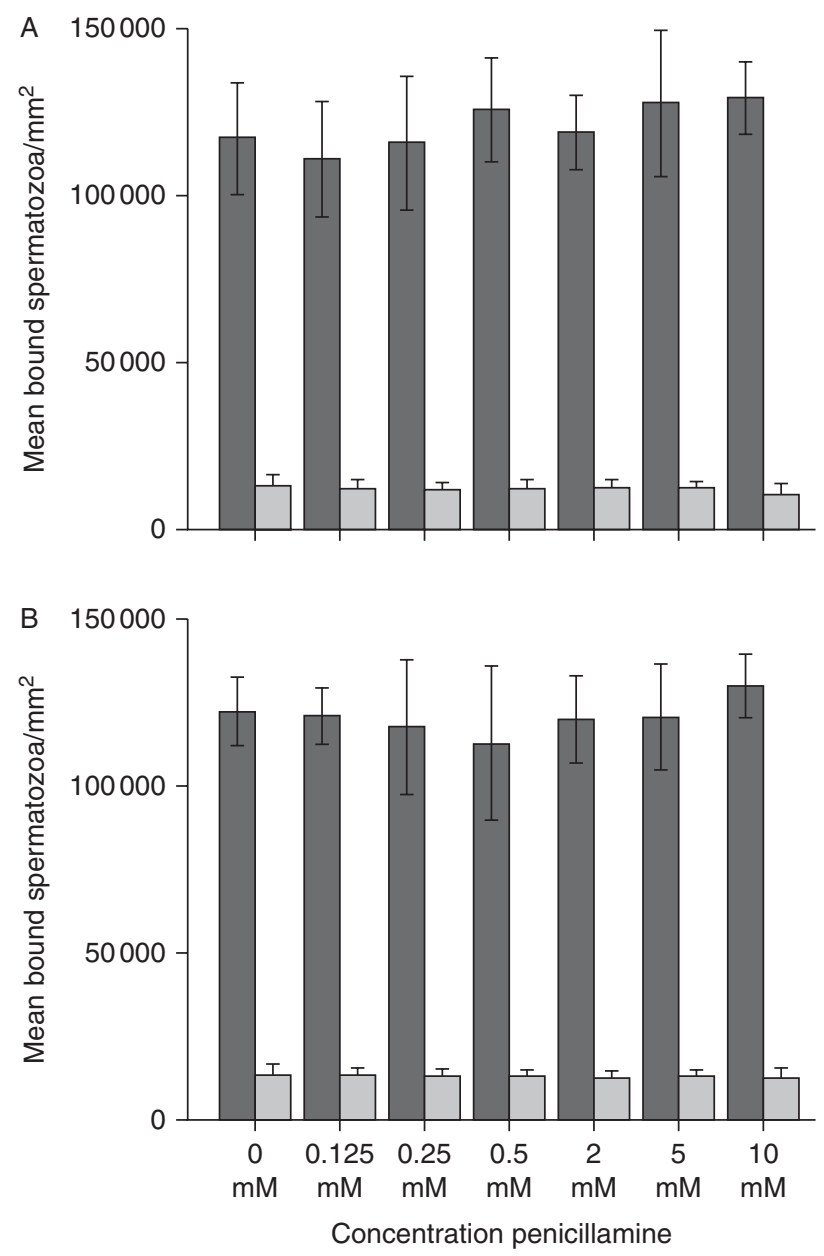

Figure 7 The effect of different concentrations of D-penicillamine $(0,0.125,0.25,0.5,1,5$ and $10 \mathrm{mM})$ on (A) initial density of equine sperm binding to oviduct explants and (B) density of sperm binding to oviduct explants after attempts to trigger release under non-capacitating (dark grey bars) and capacitating (light grey bars) conditions. No effect of D-penicillamine on sperm-oviduct binding or release was evident in either condition. Data represent mean ( \pm s.D.) number of spermatozoa bound to oviduct explants ( $n=10$ /group) over five replicates. Repeated measure ANOVA with Greenhouse-Geisser and Bonferroni correction, followed by Scheffé post hoc tests for pairwise comparison. 

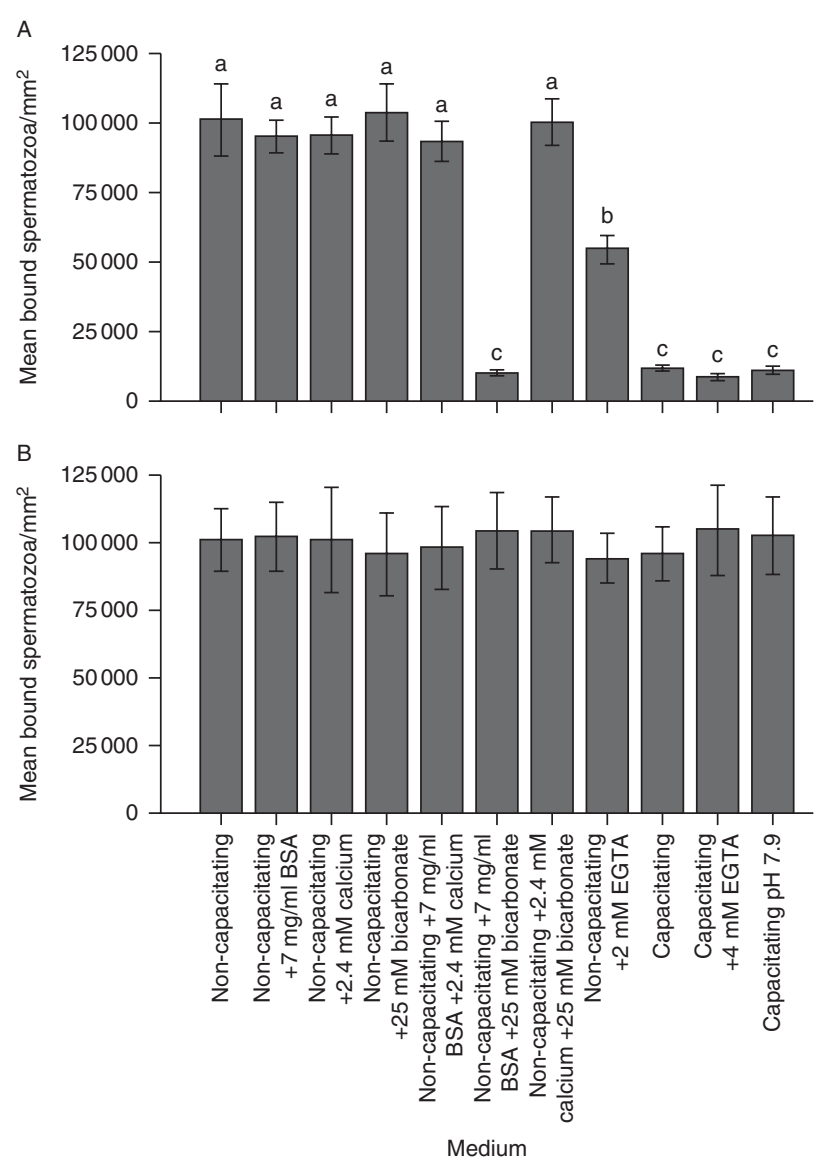

Figure 8 Individual and combined effects of albumin, $\mathrm{Ca}^{2+}, \mathrm{HCO}_{3}^{-}$and EGTA on (A) initial density of equine sperm-oviduct and (B) binding density after incubation to trigger sperm release. Data represent mean ( \pm s.D.) number of spermatozoa bound to oviduct explants $(n=10 /$ group $) / \mathrm{mm}^{2}$ over three replicates. $\mathrm{Ca}^{2+}, \mathrm{HCO}_{3}^{-}$and albumin did not affect sperm-oviduct binding density individually, whereas the combination of these three capacitating factors supported sperm-oviduct binding at a significantly lower density. Additionally, sperm-oviduct binding transpired not to be $\mathrm{Ca}^{2+}$ dependent. None of the tested conditions caused marked release of spermatozoa from the oviduct explants. Values that differ significantly are indicated by different small letters. One-way ANOVA was followed by Bonferroni post hoc tests for pairwise comparison.

Moreover, removal of $\mathrm{Ca}^{2+}$ by 4 mMEGTA in capacitating conditions did not significantly lower sperm-oviduct binding compared to the same conditions without EGTA $(P=0.98)$. These results suggest that sperm binding to oviduct epithelium is not initiated by a $\mathrm{Ca}^{2+}$-dependent lectin interaction, whereas combined exposure to $\mathrm{HCO}_{3}^{-}$ and albumin significantly reduced equine sperm-oviduct binding density.

\section{None of the glycosaminoglycans, D-penicillamine, $\mathrm{HCO}_{3}^{-}, \mathrm{Ca}^{2+}$, albumin or alkalinity $(\mathrm{pH} 7.9)$ induce release of oviduct-bound spermatozoa}

It has previously been shown that heparin (Talevi \& Gualtieri 2001) and D-penicillamine (Gualtieri et al.
2009) initiate sperm release from the bovine oviduct epithelium. Washed sperm-oviduct explants, established in non-capacitating conditions, were incubated for $2 \mathrm{~h}$ with glycosaminoglycans, D-penicillamine and/or the three major capacitation agents $\left(\mathrm{BSA}, \mathrm{Ca}^{2+}\right.$ and $\mathrm{HCO}_{3}^{-}$) added individually or in combinations. Interestingly, while the density of sperm-oviduct binding clearly decreased in the combined presence of $\mathrm{HCO}_{3}^{-}$and albumin (Fig. 8B), sperm release from oviduct explants could not be induced using glycosaminoglycans (Fig. 6D), D-penicillamine (Fig. 7B), albumin, $\mathrm{HCO}_{3}^{-}$ alone or $\mathrm{Ca}^{2+}$ (Fig. 8B). Moreover, neither capacitating conditions at $\mathrm{pH} 7.4$ nor at an elevated $\mathrm{pH} 7.9$ were able to influence the density of spermatozoa binding to oviduct explant epithelium (Fig. 8B).

\section{Role of combined $\mathrm{HCO}_{3}^{-}$and albumin in sperm concentration-dependent binding to equine oviduct explants}

To assess the effects of combined $\mathrm{HCO}_{3}^{-}$and albumin or capacitating medium $\left(\mathrm{HCO}_{3}^{-}, \mathrm{Ca}^{2+}\right.$ and albumin) on sperm binding to oviduct explants, we additionally evaluated the effect of increasing sperm concentrations $\left(1,2,5,10,25,50,75\right.$ and $100 \times 10^{6}$ spermatozoa $\left./ \mathrm{ml}\right)$ on binding to oviduct explants in non-capacitating, noncapacitating enriched with albumin and $\mathrm{HCO}_{3}^{-}$and capacitating medium. Saturation for sperm binding after 20-min pre-incubation in both combined albumin/ $\mathrm{HCO}_{3}^{-}$-enriched non-capacitating and capacitating medium was reached at $50 \times 10^{6}$ spermatozoa $/ \mathrm{ml}$ (combined albumin/ $\mathrm{HCO}_{3}^{-}$-enriched non-capacitating medium: $2.1 \pm 0.3 \times 10^{5}$ spermatozoa $/ \mathrm{mm}^{2}$; capacitating medium: $2.3 \pm 0.2 \times 10^{5}$ spermatozoa $/ \mathrm{mm}^{2}$; Fig. 9), whereas in non-capacitating medium, a similar saturation was already reached at $5 \times 10^{6}$ spermatozoa $/ \mathrm{ml}$ $\left(2.2 \pm 0.2 \times 10^{5}\right.$ spermatozoa $/ \mathrm{mm}^{2}$; Fig. 9). These results suggest that media enriched with both albumin and $\mathrm{HCO}_{3}^{-}$contain insufficient albumin and/or $\mathrm{HCO}_{3}^{-}$to reduce the binding density of sperm for oviduct epithelium in suspensions with a sperm concentration of $50 \times 10^{6} \mathrm{spermatozoa} / \mathrm{ml}$ or higher.

\section{Exposure of stallion sperm to $\mathrm{HCO}_{3}^{-}, \mathrm{Ca}^{2+}$ and albumin in combination induces head-to-head agglutination independent of external $\mathrm{Ca}^{2+}$}

As previously shown for bull (Yang et al. 2012) and boar (Harayama et al. 1998, 2000a) spermatozoa, contact with $\mathrm{HCO}_{3}^{-}, \mathrm{Ca}^{2+}$ and albumin induced rapid headto-head agglutination in suspended sperm. For this reason, we hypothesized that reduced sperm-oviduct binding in combined $\mathrm{HCO}_{3}^{-}$and albumin conditions was a product of rapid head-to-head agglutination of stallion sperm. Therefore, we examined sperm agglutination in the presence of the three capacitation agents (BSA, $\mathrm{Ca}^{2+}$ and $\mathrm{HCO}_{3}^{-}$) added individually or in 


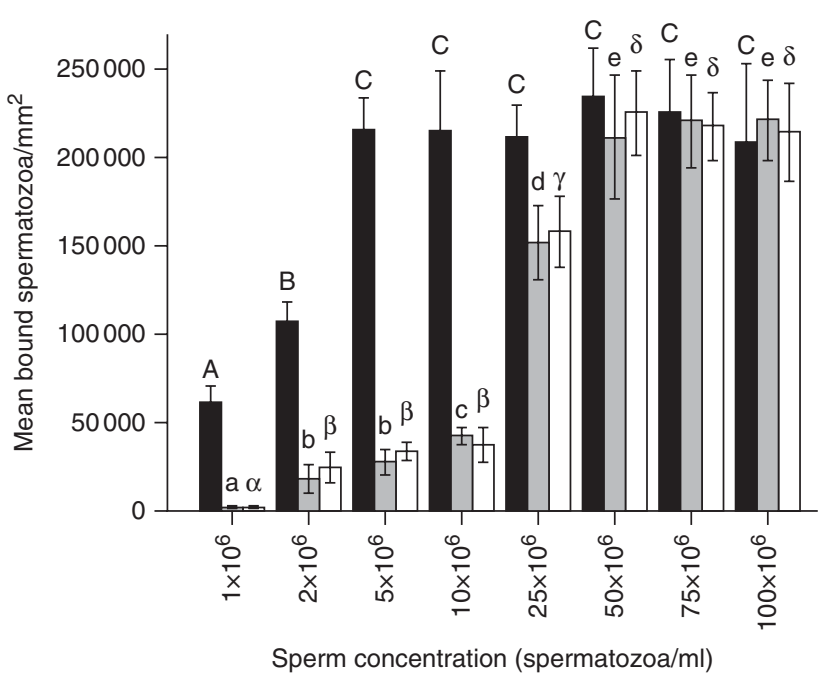

Figure 9 Effect of sperm concentration on density of stallion sperm binding to equine oviduct explants in i) non-capacitating (dark grey bars), ii) capacitating (light grey bars) and iii) $\mathrm{HCO}_{3}^{-}$/ albumin-enriched non-capacitating conditions (white bars). Saturation of sperm-oviduct explant binding was detected in non-capacitating conditions at $5 \times 10^{6}$ spermatozoa $/ \mathrm{ml}$, whereas in capacitating and $\mathrm{HCO}_{3}^{-}$/albumin-enriched non-capacitating conditions, saturation was not evident until $50 \times 10^{6}$ spermatozoa $/ \mathrm{ml}$. Data represent mean ( \pm s.D.) number of spermatozoa bound to oviduct explants ( $n=20$ /group) in three replicates. For non-capacitating conditions, values that differ significantly are indicated by different capital letters. For capacitating conditions, values that differ significantly are indicated by different small letters. For non-capacitating conditions enriched with $\mathrm{HCO}_{3}^{-}$and albumin, values that differ significantly are indicated by different Greek symbols. Results were analyzed using ANOVA with Greenhouse-Geisser correction, followed by post hoc tests after Bonferroni correction.

combinations. In comparison to non-capacitating medium $(4 \pm 1 \%)$, we observed a small but significant increase after 0.5 -h incubation in non-capacitating medium enriched with albumin $(17 \pm 6 \% ; P=0.04)$, $\mathrm{Ca}^{2+}(17 \pm 5 \% ; P=0.04)$ or $\mathrm{HCO}_{3}^{-}(16 \pm 8 \% ; P=0.03)$. Agglutination was even more pronounced when capacitating factors were combined (albumin $+\mathrm{Ca}^{2+}$ : $40 \pm 16 \% ; P=0.001$ and $\mathrm{Ca}^{2+}+\mathrm{HCO}_{3}^{-}: 39 \pm 10 \%$; $P=0.002)$. Surprisingly, incubation in combined albumin $+\mathrm{HCO}_{3}^{-}(83 \pm 10 \%)$ showed similar agglutination rates to those observed when all three capacitating factors were combined (capacitating medium; $90 \pm 4 \%$; $P=0.99)$. Moreover, sperm incubated in capacitating medium (albumin $+\mathrm{Ca}^{2+}+\mathrm{HCO}_{3}^{-}$) at elevated $\mathrm{pH} 7.9$ showed a similar agglutination rate $(91 \pm 3 \% ; P=0.99)$ (Fig. 10a and b). After 2-h incubation, similar trends were observed though agglutination rates were generally higher than at $0.5 \mathrm{~h}$ (non-capacitating, $17 \pm 7 \%$; albumin, $36 \pm 11 \% ; \mathrm{Ca}^{2+}, 28 \pm 5 \% ; \mathrm{HCO}_{3}^{-}$-enriched medium $36 \pm 11 \%$ and combined albumin $+\mathrm{Ca}^{2+}$ medium $80 \pm 8 \%$ : $P<0.01$ for all comparisons) with the exceptions of i) albumin $+\mathrm{HCO}_{3}^{-}(83 \pm 10 \% ; P=0.98)$ and ii) $\mathrm{Ca}^{2+}+\mathrm{HCO}_{3}^{-}(39 \pm 10 \% ; \quad P=0.24)$, and capacitating medium at both iii) $\mathrm{pH} 7.4(39 \pm 10 \%$; $P=0.87)$ and iv) $7.9(39 \pm 10 \% ; P=0.82)$ (Fig. 10a). Interestingly, stallion sperm agglutination in our studies was $\mathrm{Ca}^{2+}$ independent, and there was no effect on agglutination rates of adding EGTA to non-capacitating (at 0.5 h: $3 \pm 2 \% ; P=0.99$ and at 2 h: $8 \pm 1 \% ; P=0.96$ )
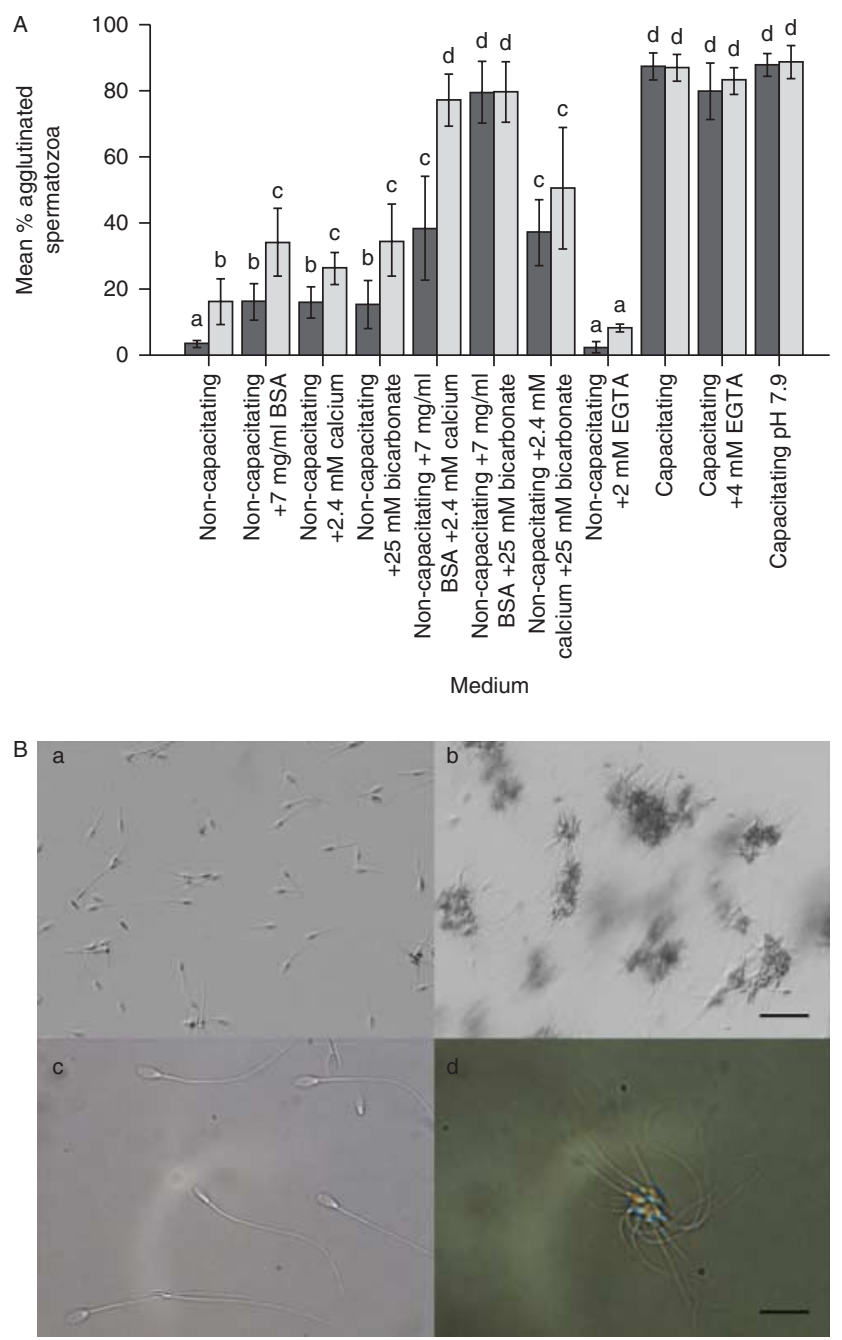

Figure 10 (A) Individual and combined effects of albumin, $\mathrm{Ca}^{2+}$, $\mathrm{HCO}_{3}^{-}$and EGTA on head-to-head stallion sperm agglutination after $0.5 \mathrm{~h}$ (dark grey) and $2 \mathrm{~h}$ (light grey) incubation. Data represent mean ( \pm s.D.) percentages of agglutinated spermatozoa $(n=200$ spermatozoa/group; three replicates). In general, the combination of $\mathrm{Ca}^{2+}, \mathrm{HCO}_{3}^{-}$and albumin induced very high rates of sperm agglutination, whereas the effects of individual capacitating factors were much lower. Moreover, sperm agglutination was shown to be $\mathrm{Ca}^{2+}$ independent. Repeated measure ANOVA with GreenhouseGeisser and Bonferroni correction, followed by Scheffé post hoc tests for pairwise comparison. (B) Light microscopic images illustrate that pre-incubated stallion sperm $\left(2 \times 10^{6}\right.$ spermatozoa $\left./ \mathrm{ml}\right)$ did not agglutinate in $(\mathrm{a}, \mathrm{c})$ medium whithout capacitating factors (non-capacitating medium), whereas in medium containing albumin, $\mathrm{Ca}^{2+}$ and $\mathrm{HCO}_{3}^{-}$(capacitating conditions: b, d), sperm rapidly agglutinated (a, b: original magnification, $400 \times$, bar $=62.5 \mu \mathrm{m}$; c, d: original magnification, $1000 \times$, bar $=25 \mu \mathrm{m}$ ). 
or capacitating medium (at $0.5 \mathrm{~h}: 83 \pm 9 \% ; P=0.97$ and at $2 \mathrm{~h}: 86 \pm 4 \% ; P=0.98$ ) (Fig. 10a).

\section{Head-to-head agglutination in combined $\mathrm{HCO}_{3}^{-}$ and albumin medium physically prevents equine sperm-oviduct binding}

It was tested whether head-to-head sperm agglutination in combined $\mathrm{HCO}_{3}^{-}$and albumin medium, which relates to the lower stallion sperm-oviduct binding densities, induced a decreased stallion sperm affinity for the oviduct epithelium or physically prevented sperm to bind to oviduct epithelium. First, the estimated number of non-agglutinated sperm cells in combined $\mathrm{HCO}_{3}^{-}$and albumin medium was compared to the number of non-agglutinated sperm cells in non-capacitating medium (Fig. 11a). At a concentration of $20 \times$ $10^{6}$ spermatozoa/ml, about $2 \times 10^{6}$ sperm cells $(10 \%)$ were not agglutinated in combined $\mathrm{HCO}_{3}^{-}$and albumin conditions which were not significantly different from the number of non-agglutinated sperm cells in noncapacitating medium $(P=0.23)$. Next, the binding property of these $2 \times 10^{6}$ non-capacitating (and thus not agglutinated; Fig. 11a) sperm suspensions were compared to the effective similar non-agglutinated sperm dose using $20 \times 10^{6}$ capacitated and thus $90 \%$ agglutinated sperm suspensions (Fig. 11b). These two conditions showed $1.3 \pm 0.1 \times 10^{5}$ bound sperm $/ \mathrm{mm}^{2}$ vs $1.1 \pm 0.1 \times 10^{5}$ bound spermatozoa $/ \mathrm{mm}^{2} \quad(P=0.11)$, indicating that sperm head-to-head agglutination facilitated by sperm capacitation physically prevents the interaction between the apical part of the sperm head and the oviduct epithelium.

\section{Discussion}

In this study, we found, in contrast to many other mammalian species, that binding of stallion spermatozoa to oviduct epithelium is not influenced by a range of carbohydrates, glycosaminoglycans, S-S reductants, lectins, $\mathrm{Ca}^{2+}$ or alkalinity ( $\mathrm{pH}$ 7.9). On the other hand, we found that the density of stallion sperm binding to the oviduct decreased when the spermatozoa had previously been exposed to $\mathrm{HCO}_{3}^{-}$and albumin combined. These results suggest that equine spermoviduct binding is not regulated by $\mathrm{Ca}^{2+}$-dependent lectin or disulfide binding. The presence of $\mathrm{HCO}_{3}^{-}$and albumin prevented physically the capacity of stallion spermatozoa to bind to oviduct epithelium primarily by rapid stimulation of head-to-head sperm agglutination, whereas sperm release from oviduct binding could not be provoked under the various tested capacitation inducing conditions.

Lectin histochemistry of the different regions of the mare's oviduct revealed that oligosaccharides with terminal $\mathrm{N}$-acetylgalactosamine moieties were the most abundant carbohydrates in the isthmus (Ball et al.
1997, Desantis et al. 2004, 2005). The expression of $\mathrm{N}$-acetylneuraminic (sialic) acid moieties on the luminal surface was lower. Desantis et al. (2004, 2005) demonstrated that these lectin-labeling patterns were
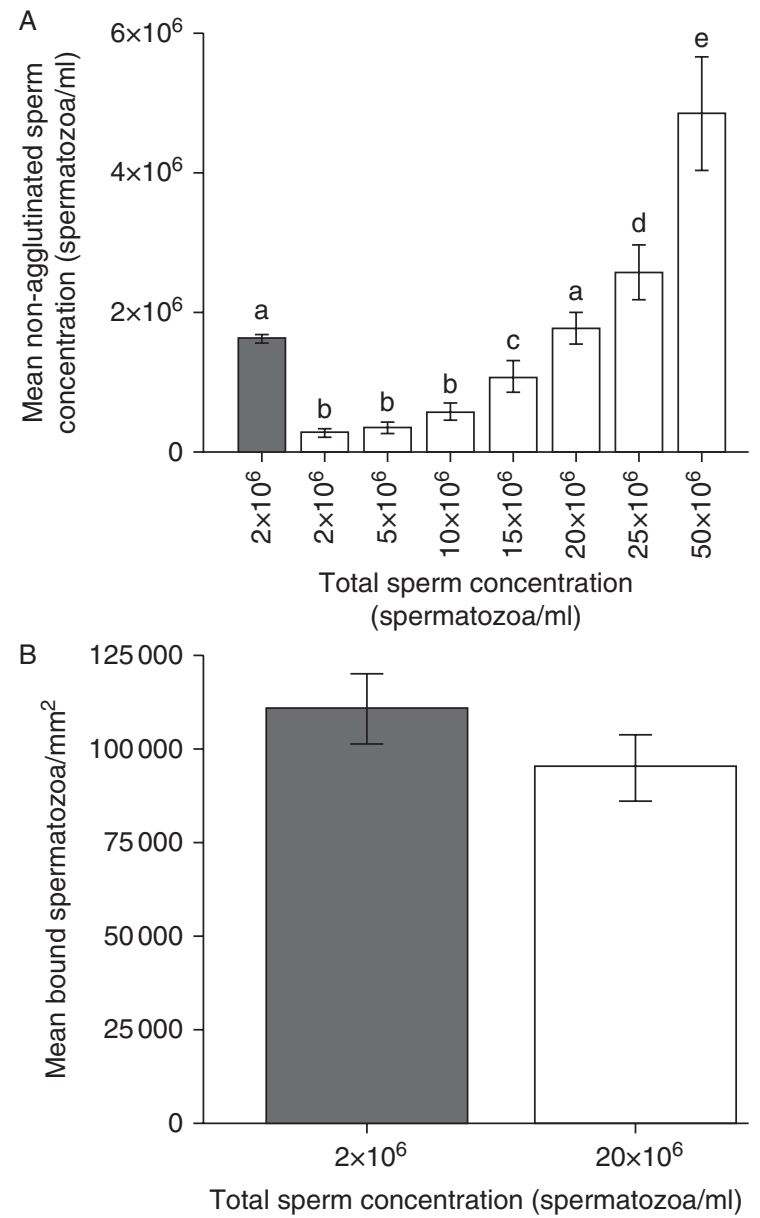

Figure 11 (A) Relationship between total and non-agglutinated stallion sperm concentration of sperm suspensions incubated under combined albumin/ $\mathrm{HCO}_{3}^{-}$-enriched non-capacitating medium (head-to-head sperm agglutination effect; white bars). Data represent mean ( \pm s.D.) non-agglutinated sperm concentrations (three replicates). Considering an analogue concentration non-agglutinated cells $\left(2 \times 10^{6}\right.$ spermatozoa $/ \mathrm{ml}$ ), a total concentration of $2 \times 10^{6}$ spermatozoa $/ \mathrm{ml}$ in noncapacitating medium (control: no head-to-head sperm agglutination effect; dark grey bar) corresponded with $20 \times 10^{6}$ spermatozoa $/ \mathrm{ml}$ in combined albumin $/ \mathrm{HCO}_{3}^{-}$medium. Values that differ significantly are indicated by different small letters. One-way ANOVA was followed by Bonferroni post hoc tests for pairwise comparison. (B) Comparison between the density of stallion sperm binding to equine oviduct explants after exposure to a sperm suspension of $2 \times 10^{6}$ spermatozoa $/ \mathrm{ml}$ in non-capacitating medium (dark grey bar) and $20 \times$ $10^{6}$ spermatozoa $/ \mathrm{ml}$ in combined albumin and $\mathrm{HCO}_{3}^{-}$-enriched non-capacitating medium (both conditions contain $2 \times 10^{6}$ non-agglutinated spermatozoa per $\mathrm{ml}$ ). Data represent mean ( \pm s.D. $)$ number of spermatozoa bound to oviduct explants $(n=10 /$ group $) / \mathrm{mm}^{2}$ over three replicates under i) non-capacitating (dark grey bar) and ii) combined albumin and $\mathrm{HCO}_{3}^{-}$-enriched non-capacitating (white bars) conditions. One-way ANOVA was followed by Bonferroni post hoc tests for pairwise comparison. 
very similar in both the isthmus and the ampulla, indicating that carbohydrate moieties are fairly uniformly distributed throughout the complete oviduct where they act as potential receptors for sperm binding. Moreover, in cattle studies, it has been shown that the sperm binding capacity of the isthmic and ampullary epithelium is almost identical (Lefebvre et al. 1995a, Sostaric et al. 2008). For these reasons, we hypothesized that sperm-oviduct binding is not determined by oviduct location. We subsequently used equine oviduct epithelial explants and APM harvested from the ampullary-isthmic junction as an in vitro model for the sperm-oviduct reservoir, as it is not practically feasible to collect epithelial cells exclusively from the tiny and very tortuous isthmus.

Oviduct monolayers have been used extensively in earlier in vitro studies of sperm-oviduct binding (Hayase et al. 1992, Ellington et al. 1993, Thomas et al. 1995, Dobrinski et al. 1996a). However, because morphological and ultrastructural features, and consequently the membrane molecular expression patterns are much better preserved, we preferred oviduct explants (Nelis et al. 2014). With regard to the quantification of sperm-oviduct binding, we were aware that standardization was a challenge when using equine oviduct explants because of the invaginated and irregular oviductal surface, which is very different from the flattened surface of an oviduct monolayer (Thomas et al. 1995, Dobrinski et al. 1999). To improve accuracy in the competitive sperm-oviduct binding assay, we developed a more standardized oviduct APM assay to quantify the binding densities of pre-treated sperm. The oviduct apical membranes still displayed the salient surface organelles (e.g. cilia and microvilli) of the oviduct plasma membrane while a more flattened surface was achieved. However, this model required many oviducts, whereas the supply was limited. Therefore, only competitive carbohydrate/glycosaminoglycan inhibition of sperm-oviduct binding and the effect of $\mathrm{N}$-glycosidase activity were tested using this APM assay. Nevertheless, concordance between the two assays was high, and the results of the oviduct explant assay can be considered as a validation of the APM assay.

Carbohydrate moiety expression on oviduct explants was unchanged after overnight culture. In accordance with Desantis et al. (2004, 2005) who examined oviduct tissue sections, $\mathrm{N}$-acetylgalactosamine moieties were highly expressed on the surface of oviduct explants (DBA and HPA +++ ). Interestingly, our study revealed considerable expression of $\mathrm{N}$-acetylneuraminic (sialic) acid (SNA +++ ), $\boldsymbol{\alpha}$-D-mannose and/or $\boldsymbol{\alpha}$-D-glucose moieties (Con A, LCA and PSA +++ ) on epithelium of oviduct explants. The negligible histochemical PNA signal on oviduct sections (Desantis et al. 2004, 2005) and explants indicates that D-galactose is not the ultimate critical carbohydrate mediating sperm-oviduct binding in the horse, as previously suggested (Lefebvre et al. 1995b, Dobrinski et al. 1996a).

The potential participation of a broad range of carbohydrates and polysaccharides (D-galactose, $\mathrm{N}$-acetylgalactosamine, $\mathrm{N}$-acetylglucosamine, asialofetuin, fetuin, D-fucose, fucoidan, D-mannose, mannan and $\mathrm{N}$-acetylneuraminic (sialic) acid) in sperm-oviduct interaction was tested in the current study using concentrations similar to those used by Dobrinski et al. (1996a). Fetuin is a polysaccharide that expresses several terminal carbohydrates: $\mathrm{N}$-acetylneuraminic (sialic) acid, N-acetylgalactosamine, D-galactose, $\mathrm{N}$-acetylglucosamine and D-fucose (Hayase et al. 1992) while asialofetuin expresses identical carbohydrates but has a higher ratio of galactosyl residues (Dam et al. 2005, Motoyama et al. 2011). Pre-incubating sperm suspensions with any of these carbohydrates, including D-galactose, did not inhibit sperm-oviduct binding in either non-capacitating $\left(\mathrm{Ca}^{2}+\right.$ free) or capacitating $\left(\mathrm{Ca}^{2+}\right.$ containing) conditions, as evaluated by both assays (oviduct explant or oviduct APM). Using the converse approach, i.e. inhibition of sperm-oviduct binding by pre-incubating oviduct explants with various lectins, at concentrations similar to those described by Desantis et al. (2004, 2005), also failed to inhibit sperm binding. In addition, sperm-oviduct binding was not decreased when $\mathrm{N}$-linked carbohydrates were removed by $\mathrm{N}$-glycosidase $\mathrm{F}$ (PNGase). When interpreting these results, a few points need to be considered: i) not only the type of carbohydrate but also the carbohydrate conformation/isomer is important; ii) a secondary binding can possibly be facilitated after competing with a primary carbohydrate receptor; iii) the cooperation of carbohydrates to facilitate sperm-oviduct binding; and iv) a higher sperm-oviduct binding density was observed in $\mathrm{Ca}^{2+}$-free or non-capacitating conditions than in capacitating medium containing $\mathrm{Ca}^{2+}$. Although EGTA addition reduced sperm-oviduct binding, the number of spermatozoa bound to oviduct explant epithelium was still high. The change in sperm binding capacity in the presence of EGTA appears to be primarily due to a depression of sperm motility by $\mathrm{Ca}^{2+}$ removal after 30 min of co-incubation (data not shown). As a result, spermatozoa exposed to EGTA may have had less time to reach the oviduct explants and establish binding in the $50 \mu \mathrm{l}$ medium droplet. Importantly, the supposed $\mathrm{Ca}^{2+}$ independency supports the carbohydrate insensitivity of sperm-oviduct binding, as lectin binding is mainly regulated by $\mathrm{Ca}^{2+}$. This in turn supports the hypothesis that equine sperm-oviduct affinity is not primarily a factor of $\mathrm{Ca}^{2+}$-dependent lectin binding. Considering the findings above, one could question whether the $\mathrm{Ca}^{2+}$-dependent carbohydrate-protein (lectin) interactions demonstrated between sperm and oviduct epithelial cells in vitro in a few mammalian species represent i) the totality of the pre-ovulatory sperm-oviduct binding reaction or ii) only 
a part of that reaction. (Hunter 2003) previously hypothesized the latter and suggested that there may be considerable non-specific binding in vivo. This hypothesis was illustrated by studies in the pig that showed similar sperm binding density to tracheal epithelium, containing another type of ciliary epithelial cell (Hunter 2003, 2011). In contrast, in man, a sequence of three amino acids (Arg-Gly-Asp) is thought to play an important regulatory role in sperm-oviduct interaction (Reeve et al. 2003).

We also found that sperm-oviduct binding could not be inhibited by pre-incubating sperm with different glycosaminoglycans: chondroitin sulfate, dextran sulfate, heparan sulfate, heparin, hyaluronic acid and keratan sulfate, at concentrations based on the study of Sostaric et al. (2005). Neither could these molecules induce sperm release from oviduct explant binding. In cattle, an obvious effect of sulfated glycosaminoglycans on sperm-oviduct release (Gualtieri et al. 2009, 2010), capacitation/protein tyrosine phosphorylation (Parrish et al. 1988, Bergqvist et al. 2007, Gualtieri et al. 2010, Parrish 2014) and fertilization (Parrish et al. 1988, Parrish 2014) has been shown. In the mare, a high concentration of these molecules has been reported in follicular fluid and oviductal fluid, but in our study, different types of glycosaminoglycans were unable to reduce density of stallion spermatozoa binding to oviduct epithelia. Moreover, the tested glycosaminoglycans also had no effect on sperm capacitation parameters such as tail-associated protein tyrosine phosphorylation and, presumably, play no role in equine sperm capacitation. D-penicillamine also failed to inhibit sperm-oviduct binding or induce sperm release from oviduct epithelium at concentrations based on the report of Aitken et al. (2012) that in vitro motility of stallion sperm could be preserved by disulfide reductants like D-penicillamine. In cattle, disulfide reductants did facilitate sperm release from oviduct epithelium by reducing disulfide covalent bonds to sulfhydryl groups (Gualtieri et al. 2009). Our results clearly demonstrate that sperm-oviduct binding in the horse is not dependent on disulfide covalent bonds.

Combined $\mathrm{HCO}_{3}^{-}$and albumin enrichment of incubation media did cause a clear decline in density of sperm binding to oviduct epithelium ( $>10$-fold), associated with rapid induction of sperm head-to-head agglutination. Both characteristics were independent of $\mathrm{Ca}^{2+}$ and alkalinity ( $\mathrm{pH}$ 7.9). Sperm agglutination is a common event during manipulation of sperm from many mammalian species and is a problem during in vitro sperm studies because it interferes with accurate sperm assessment. Sperm agglutination occurs between spermatozoa with intact plasma and acrosome membranes (Yang et al. 2012). Typically head-to-head agglutination takes place when sperm is exposed in vitro to: i) washing media (ram (Dott \& Walton 1960)), ii) fluids from the female genital tract (bull (Lindahl 1966)), iii) divalent cations (rabbit (Bedford 1970), bull (Lindahl 1973), iv) bovine serum in combination with semen extender (bull (Senger \& Saacke 1976)) and v) IVF medium (boar (Harayama et al. 1998, 2000a)). Divalent cations (including $\mathrm{Ca}^{2+}, \mathrm{Mg}^{2+}$ and $\mathrm{Mn}^{2+}$ ) activate an ATPdependent surface reaction which triggers head-to-head sperm agglutination (Harayama et al. 1998, 2000a, Yang et al. 2012). Alternatively, sperm head-to-head agglutination is also observed in an early stage of the capacitation process in vitro when anti-agglutinin is removed from the sperm surface (Lindahl \& Sjoblom 1981, Harayama et al. 2000b). As sperm agglutination in this study occurs independently from $\mathrm{Ca}^{2+}$, we hypothesize that in combined $\mathrm{HCO}_{3}^{-}$and albumin medium, anti-agglutinin is released from the sperm plasma membrane over the acrosomal region of the stallion sperm, as such revealing previously 'hidden' receptors on the sperm plasma membrane and enabling sperm-specific head-to-head agglutination interactions. In the pig, Harayama et al. (1996, 1999) observed an analog anti-agglutinin release from boar sperm exposed to capacitating media.

As a consequence of the observed sperm head-to-head agglutination in our experiments, putative sperm plasma membrane receptors in the apical ridge were physically no longer available for oviduct binding. Moreover, we demonstrated that combined albumin and $\mathrm{HCO}_{3}^{-}$ conditions did not induce a concomitant reduction in affinity of stallion sperm for oviduct epithelium. In general, it is thought that a sperm's capacitation status determines its ability to interact with oviduct epithelium (Suarez 2001). In pig spermatozoa, $\mathrm{HCO}_{3}^{-}$initiates rapid cAMP-driven membrane changes (Flesch et al. 2001) that permit albumin-dependent cholesterol removal, followed by a series of functional membrane changes required for the acquisition of fertilizing potential (van Gestel et al. 2005, 2007, Tsai et al. 2010, 2012). In support of this hypothesis, it was previously reported that exposure of bull sperm to $\mathrm{HCO}_{3}^{-}$resulted in decreased affinity for the D-fucose moieties involved in spermoviduct interaction (Sostaric et al. 2005). However, current equine sperm capacitation media are still unable to induce full capacitation and only reduce the ability of stallion sperm to bind to oviduct epithelium by inducing sperm head-to-head agglutination. The effective number of non-agglutinated spermatozoa in suspension determines the sperm binding density of the oviduct epithelium. The fact that oviduct pre-bound, nonagglutinated spermatozoa were not released after a capacitation treatment might be explained by the fact that these cells already used their carbohydrate moieties to bind to the oviduct epithelium and cannot use them for the capacitation-dependent head-to-head agglutination anymore. In further research, we would like to investigate the role of early plasma membrane changes, cholesterol removal and other capacitation-induced surface changes possibly involved in sperm-oviduct binding and/or sperm head-to-head agglutination. 
In conclusion, equine sperm-oviduct binding is independent of a range of tested carbohydrates, S-S reductants, $\mathrm{Ca}^{2+}$ and alkalinity $(\mathrm{pH} 7.9)$, whereas preincubation in media containing both $\mathrm{HCO}_{3}^{-}$and albumin reduced sperm-oviduct binding density. We hypothesize that the requirement for sperm-oviduct binding is dependent on the timing of insemination. If mating or insemination occurs during early estrus, sperm may need to survive several days until ovulation is imminent, and sperm-oviduct interaction may be critical to an adequate longevity of sperm viability (Dobrinski et al. 1996b, 1997). By contrast, if sperm enters the oviduct during the pre-ovulatory period, assuming increased albumin and $\mathrm{HCO}_{3}^{-}$levels, sperm will be physically prevented to interact with the sperm reservoir. This would allow $\mathrm{HCO}_{3}^{-}$and albumin exposed sperm to proceed immediately along the mare's oviduct to the site of fertilization without an obligatory period of epithelial binding. Nevertheless, sperm bound to oviduct epithelium should be able to react to capacitation triggers in the oviduct, such as elevated pH (Leemans et al. 2014, 2015), to achieve full fertilizing capability. Full and proper initiation of capacitation will presumably release sperm optimally primed to fertilize from the oviduct epithelium (Leemans et al. 2015).

\section{Supplementary data}

This is linked to the online version of the paper at http://dx.doi. org/10.1530/REP-15-0471.

\section{Declaration of interest}

The authors declare that there is no conflict of interest that could be perceived as prejudicing the impartially of the research reported.

\section{Funding}

This work was supported by the Agency for Innovation in Science and Technology (IWT-Flanders; grant number 101521).

\section{Acknowledgements}

The authors wish to thank Petra Van Damme and Isabel Lemahieu for their excellent technical assistance. Fresh stallion semen was kindly provided by the clinic of Reproduction and Obstetrics of Large Animals, Merelbeke, Belgium.

\section{References}

Aitken RJ, Gibb Z, Mitchell LA, Lambourne SR, Connaughton HS \& De Iuliis GN 2012 Sperm motility is lost in vitro as a consequence of mitochondrial free radical production and the generation of electrophilic aldehydes but can be significantly rescued by the presence of nucleophilic thiols. Biology of Reproduction 87 110. (doi:10.1095/ biolreprod.112.102020)
Bader H 1982 An investigation of sperm migration into the oviducts of the mare. Journal of Reproduction and Fertility. Supplement 32 59-64.

Ball BA, Dobrinski I, Fagnan MS \& Thomas PG 1997 Distribution of glycoconjugates in the uterine tube (oviduct) of horses. American Journal of Veterinary Research 58 816-822.

Bedford JM 1970 Observations on some properties of a potent sperm-head agglutinin in the semen of a fertile rabbit. Journal of Reproduction and Fertility 22 193-198. (doi:10.1530/jrf.0.0220193)

Bergqvist AS, Ballester J, Johannisson A, Lundeheim N \& RodriguezMartinez H 2007 Heparin and dermatan sulphate induced capacitation of frozen-thawed bull spermatozoa measured by merocyanine- 540 . Zygote 15 225-232. (doi:10.1017/S0967199407004182)

Boilard M, Bailey J, Collin S, Dufour M \& Sirard MA 2002 Effect of bovine oviduct epithelial cell apical plasma membranes on sperm function assessed by a novel flow cytometric approach. Biology of Reproduction 67 1125-1132. (doi:10.1095/biolreprod67.4.1125)

Dam TK, Gabius HJ, Andre S, Kaltner H, Lensch M \& Brewer CF 2005 Galectins bind to the multivalent glycoprotein asialofetuin with enhanced affinities and a gradient of decreasing binding constants. Biochemistry 44 12564-12571. (doi:10.1021/bi051144z)

DeMott RP, Lefebvre R \& Suarez SS 1995 Carbohydrates mediate the adherence of hamster sperm to oviductal epithelium. Biology of Reproduction 52 1395-1403. (doi:10.1095/biolreprod52.6.1395)

Desantis S, Acone F, Corriero A, Deflorio M, Zubani D, Ventriglia G, Palmieri G \& De Metrio G 2004 Distribution of sialoglycoconjugates in the oviductal isthmus of the horse during anoestrus, oestrus and pregnancy: a lectin histochemistry study. European Journal of Histochemistry 48 403-412. (doi:10.4081/914)

Desantis S, Ventriglia G, Zubani D, Corriero A, Deflorio M, Acone F, Palmieri G \& De Metrio G 2005 Differential lectin binding patterns in the oviductal ampulla of the horse during oestrus. European Journal of Histochemistry 49 139-149.

Dobrinski I, Ignotz GG, Thomas PG \& Ball BA 1996a Role of carbohydrates in the attachment of equine spermatozoa to uterine tubal (oviductal) epithelial cells in vitro. American Journal of Veterinary Research 57 1635-1639.

Dobrinski I, Suarez SS \& Ball BA 1996 Intracellular calcium concentration in equine spermatozoa attached to oviductal epithelial cells in vitro. Biology of Reproduction 54 783-788. (doi:10.1095/biolreprod54.4.783)

Dobrinski I, Smith TT, Suarez SS \& Ball BA 1997 Membrane contact with oviductal epithelium modulates the intracellular calcium concentration of equine spermatozoa in vitro. Biology of Reproduction 56 861-869. (doi:10.1095/biolreprod56.4.861)

Dobrinski I, Jacob JR, Tennant BC \& Ball BA 1999 Generation of an equine oviductal epithelial cell line for the study of sperm-oviduct interactions. Theriogenology 52 875-885. (doi:10.1016/S0093-691X(99)00179-X)

Dott HM \& Walton A 1960 Effects of dilution and washing on ram spermatozoa studied by the flow dialysis technique. Journal of Reproduction and Fertility 1 350-367. (doi:10.1530/jrf.0.0010350)

Ellington JE, Ignotz GG, Varner DD, Marcucio RS, Mathison P \& Ball BA 1993 In vitro interaction between oviduct epithelial and equine sperm. Archives of Andrology 31 79-86. (doi:10.3109/01485019308988384)

Flesch FM, Voorhout WF, Colenbrander B, van Golde LM \& Gadella BM 1998 Use of lectins to characterize plasma membrane preparations from boar spermatozoa: a novel technique for monitoring membrane purity and quantity. Biology of Reproduction 59 1530-1539. (doi:10.1095/ biolreprod59.6.1530)

Flesch FM, Brouwers JF, Nievelstein PF, Verkleij AJ, van Golde LM, Colenbrander B \& Gadella BM 2001 Bicarbonate stimulated phospholipid scrambling induces cholesterol redistribution and enables cholesterol depletion in the sperm plasma membrane. Journal of Cell Science 114 3543-3555.

van Gestel RA, Brewis IA, Ashton PR, Helms JB, Brouwers JF \& Gadella BM 2005 Capacitation-dependent concentration of lipid rafts in the apical ridge head area of porcine sperm cells. Molecular Human Reproduction 11 583-590. (doi:10.1093/molehr/gah200)

van Gestel RA, Brewis IA, Ashton PR, Brouwers JF \& Gadella BM 2007 Multiple proteins present in purified porcine sperm apical plasma membranes interact with the zona pellucida of the oocyte. Molecular Human Reproduction 13 445-454. (doi:10.1093/molehr/gam030) 
Gualtieri R \& Talevi R 2000 In vitro-cultured bovine oviductal cells bind acrosome-intact sperm and retain this ability upon sperm release. Biology of Reproduction 62 1754-1762. (doi:10.1095/biolreprod62. 6.1754)

Gualtieri R, Boni R, Tosti E, Zagami M \& Talevi R 2005 Intracellular calcium and protein tyrosine phosphorylation during the release of bovine sperm adhering to the fallopian tube epithelium in vitro. Reproduction 129 51-60. (doi:10.1530/rep.1.00374)

Gualtieri R, Mollo V, Duma G \& Talevi R 2009 Redox control of surface protein sulphhydryls in bovine spermatozoa reversibly modulates sperm adhesion to the oviductal epithelium and capacitation. Reproduction 138 33-43. (doi:10.1530/REP-08-0514)

Gualtieri R, Mollo V, Barbato V \& Talevi R 2010 Ability of sulfated glycoconjugates and disulfide-reductants to release bovine epididymal sperm bound to the oviductal epithelium in vitro. Theriogenology $\mathbf{7 3}$ 1037-1043. (doi:10.1016/j.theriogenology.2009.11.030)

Harayama H, Kato S \& Hammerstedt RH 1996 Electrophoretic characterization of boar epididymal antiagglutinin. Biology of Reproduction $\mathbf{5 5}$ 325-332. (doi:10.1095/biolreprod55.2.325)

Harayama H, Miyake M, Shidara O, Iwamoto E \& Kato S 1998 Effects of calcium and bicarbonate on head-to-head agglutination in ejaculated boar spermatozoa. Reproduction, Fertility, and Development 10 445-450. (doi:10.1071/RD98124)

Harayama H, Magargee SF, Kunze E, Shidara O, Iwamoto E, Arikawa S, Miyake M, Kato S \& Hammerstedt RH 1999 Changes in epididymal protein anti-agglutinin on ejaculated boar spermatozoa during capacitation in vitro. Reproduction, Fertility, and Development 11 193-199. (doi:10.1071/RD99056)

Harayama H, Liao PC, Gage DA, Miyake M, Kato S \& Hammerstedt RH 2000a Biochemical characterization of sialoprotein "anti-agglutinin" purified from boar epididymal and seminal plasma. Molecular Reproduction and Development 55 96-103. (doi:10.1002/(SICI)10982795(200001)55:1 <96::AID-MRD13>3.0.CO;2-J)

Harayama H, Miyake M \& Kato S $2000 b$ Role of cyclic adenosine 3',5'monophosphate and serum albumin in head-to-head agglutination of boar spermatozoa. Reproduction, Fertility, and Development 12 307-318. (doi:10.1071/RD00030)

Harper MJ 1973 Stimulation of sperm movement from the isthmus to the site of fertilization in the rabbit oviduct. Biology of Reproduction 8 369-377.

Hayase T, Rice KG, Dziegielewska KM, Kuhlenschmidt M, Reilly T \& Lee YC 1992 Comparison of $\mathrm{N}$-glycosides of fetuins from different species and human $\alpha$ 2-HS-glycoprotein. Biochemistry 31 4915-4921. (doi:10.1021/bi00135a024)

Holt WV 2011 Mechanisms of sperm storage in the female reproductive tract: an interspecies comparison. Reproduction in Domestic Animals 46 (Suppl 2) 68-74. (doi:10.1111/j.1439-0531.2011.01862.x)

Hunter RH 1981 Sperm transport and reservoirs in the pig oviduct in relation to the time of ovulation. Journal of Reproduction and Fertility $\mathbf{6 3}$ 109-117. (doi:10.1530/jrf.0.0630109)

Hunter RH 2003 Reflections upon sperm-endosalpingeal and sperm-zona pellucida interactions in vivo and in vitro. Reproduction in Domestic Animals 38 147-154. (doi:10.1046/j.1439-0531.2003.00402.x)

Hunter RH 2011 Sperm head binding to epithelium of the oviduct isthmus is not an essential preliminary to mammalian fertilization - review. Zygote 19 265-269. (doi:10.1017/S0967199410000341)

Hunter RH \& Nichol R 1983 Transport of spermatozoa in the sheep oviduct: preovulatory sequestering of cells in the caudal isthmus. Journal of Experimental Zoology 228 121-128. (doi:10.1002/jez.1402280113)

Hunter RH \& Wilmut I 1984 Sperm transport in the cow: peri-ovulatory redistribution of viable cells within the oviduct. Reproduction, Nutrition, Development 24 597-608. (doi:10.1051/rnd:19840508)

Hunter RH, Flechon B \& Flechon JE 1991 Distribution, morphology and epithelial interactions of bovine spermatozoa in the oviduct before and after ovulation: a scanning electron microscope study. Tissue Cell 23 641-656. (doi:10.1016/0040-8166(91)90020-T)

Kadirvel G, Machado SA, Korneli C, Collins E, Miller P, Bess KN, Aoki K, Tiemeyer M, Bovin N \& Miller DJ 2012 Porcine sperm bind to specific 6 -sialylated biantennary glycans to form the oviduct reservoir. Biology of Reproduction 87 147. (doi:10.1095/biolreprod.112.103879)
Leemans B, Gadella BM, Sostaric E, Nelis H, Stout TA, Hoogewijs M \& Van Soom A 2014 Oviduct binding and elevated environmental ph induce protein tyrosine phosphorylation in stallion spermatozoa. Biology of Reproduction 91 13. (doi:10.1095/biolreprod.113.116418)

Leemans B, Gadella BM, Stout TA, Nelis H, Hoogewijs M \& Van Soom A 2015 An alkaline follicular fluid fraction induces capacitation and limited release of oviduct epithelium-bound stallion sperm. Reproduction 150 193-208. (doi:10.1530/REP-15-0178)

Lefebvre R, Chenoweth PJ, Drost M, LeClear CT, MacCubbin M, Dutton JT \& Suarez SS 1995a Characterization of the oviductal sperm reservoir in cattle. Biology of Reproduction 53 1066-1074. (doi:10.1095/biolreprod53.5.1066)

Lefebvre R, DeMott R, Suarez S \& Samper J 1995b Specific inhibition of equine sperm binding to oviductal epithelium. In Equine Reproduction VI (Biology of Reproduction Monograph 1), pp 689-696. Eds D Sharp \& FW Bazer. Madison, WI: Society for the Study of Reproduction.

Lefebvre R, Lo MC \& Suarez SS 1997 Bovine sperm binding to oviductal epithelium involves fucose recognition. Biology of Reproduction $\mathbf{5 6}$ 1198-1204. (doi:10.1095/biolreprod56.5.1198)

Lindahl PE 1966 Sperm agglutinating and anti-agglutinating factors in normal follicular fluid from cattle. International Journal of Fertility $\mathbf{1 1}$ 297-305.

Lindahl PE 1973 Activators of the ATP-dependent surface reaction in the apical cell membrane of the bull-sperm head, causing head-to-head association. Experimental Cell Research 81 413-431. (doi:10.1016/ 0014-4827(73)90531-4)

Lindahl PE \& Sjoblom P 1981 On mechanisms of head-to-head association in bovine spermatozoa. Biology of Reproduction 25 29-43. (doi:10.1095/ biolreprod25.1.29)

Loux SC, Crawford KR, Ing NH, Gonzalez-Fernandez L, Macias-Garcia B, Love CC, Varner DD, Velez IC, Choi YH \& Hinrichs K 2013 CatSper and the relationship of hyperactivated motility to intracellular calcium and $\mathrm{pH}$ kinetics in equine sperm. Biology of Reproduction 89123. (doi:10.1095/biolreprod.113.111708)

McPartlin LA, Littell J, Mark E, Nelson JL, Travis AJ \& Bedford-Guaus SJ 2008 A defined medium supports changes consistent with capacitation in stallion sperm, as evidenced by increases in protein tyrosine phosphorylation and high rates of acrosomal exocytosis. Theriogenology 69 639-650. (doi:10.1016/j.theriogenology.2007.11.016)

Motoyama K, Nakashima Y, Aramaki Y, Hirayama F, Uekama K \& Arima H 2011 In Vitro gene delivery mediated by asialofetuin-appended cationic liposomes associated with $\gamma$-cyclodextrin into hepatocytes. Journal of Drug Delivery 2011 476137. (doi:10.1155/2011/476137)

Nelis H, D'Herde K, Goossens K, Vandenberghe L, Leemans B, Forier K, Smits K, Braeckmans K, Peelman L \& Van Soom A 2014 Equine oviduct explant culture: a basic model to decipher embryo-maternal communication. Reproduction, Fertility, and Development 26 954-966. (doi:10.1071/RD13089)

Parrish JJ 2014 Bovine in vitro fertilization: in vitro oocyte maturation and sperm capacitation with heparin. Theriogenology 81 67-73. (doi:10.1016/j.theriogenology.2013.08.005)

Parrish JJ, Susko-Parrish J, Winer MA \& First NL 1988 Capacitation of bovine sperm by heparin. Biology of Reproduction 38 1171-1180. (doi:10.1095/biolreprod38.5.1171)

Parrish JJ, Susko-Parrish JL \& First NL 1989a Capacitation of bovine sperm by heparin: inhibitory effect of glucose and role of intracellular $\mathrm{pH}$. Biology of Reproduction 41 683-699. (doi:10.1095/biolreprod41.4.683)

Parrish JJ, Susko-Parrish JL, Handrow RR, Sims MM \& First NL 1989b Capacitation of bovine spermatozoa by oviduct fluid. Biology of Reproduction 40 1020-1025. (doi:10.1095/biolreprod40.5.1020)

Rath D, Long CR, Dobrinsky JR, Welch GR, Schreier LL \& Johnson LA 1999 In vitro production of sexed embryos for gender preselection: high-speed sorting of X-chromosome-bearing sperm to produce pigs after embryo transfer. Journal of Animal Science 77 3346-3352.

Reeve L, Ledger WL \& Pacey AA 2003 Does the Arg-Gly-Asp (RGD) adhesion sequence play a role in mediating sperm interaction with the human endosalpinx? Human Reproduction 18 1461-1468. (doi:10.1093/humrep/deg296)

Roth J 2002 Protein N-glycosylation along the secretory pathway: relationship to organelle topography and function, protein quality control, cell interactions. Chemical Reviews 102 285-303. (doi:10.1021/ cr000423j) 
Sabeur K \& Ball BA 2007 Characterization of galactose-binding proteins in equine testis and spermatozoa. Animal Reproduction Science 101 74-84. (doi:10.1016/j.anireprosci.2006.08.028)

Scott MA, Liu IK, Overstreet JW \& Enders AC 2000 The structural morphology and epithelial association of spermatozoa at the uterotubal junction: a descriptive study of equine spermatozoa in situ using scanning electron microscopy. Journal of Reproduction and Fertility. Supplement 415-421.

Senger PL \& Saacke RG 1976 Serum-induced head-to-head agglutination of bovine spermatozoa. Journal of Reproduction and Fertility 47 215-219. (doi:10.1530/jrf.0.0470215)

Smith TT \& Nothnick WB 1997 Role of direct contact between spermatozoa and oviductal epithelial cells in maintaining rabbit sperm viability. Biology of Reproduction 56 83-89. (doi:10.1095/biolreprod56.1.83)

Sorensen MB, Stoltenberg M, Danscher G \& Ernst E 1999 Chelation of intracellular zinc ions affects human sperm cell motility. Molecular Human Reproduction 5 338-341. (doi:10.1093/molehr/5.4.338)

Sostaric E, van de Lest CH, Colenbrander B \& Gadella BM 2005 Dynamics of carbohydrate affinities at the cell surface of capacitating bovine sperm cells. Biology of Reproduction 72 346-357. (doi:10.1095/biolreprod. 104.029330)

Sostaric E, Dieleman SJ, van de Lest CH, Colenbrander B, Vos PL, GarciaGil N \& Gadella BM 2008 Sperm binding properties and secretory activity of the bovine oviduct immediately before and after ovulation. Molecular Reproduction and Development 75 60-74. (doi:10.1002/mrd.20766)

Suarez SS 1987 Sperm transport and motility in the mouse oviduct: observations in situ. Biology of Reproduction 36 203-210. (doi:10.1095/ biolreprod36.1.203)

Suarez SS 1998 The oviductal sperm reservoir in mammals: mechanisms of formation. Biology of Reproduction 58 1105-1107. (doi:10.1095/ biolreprod58.5.1105)

Suarez SS 2001 Carbohydrate-mediated formation of the oviductal sperm reservoir in mammals. Cells, Tissues, Organs 168 105-112. (doi:10.1159/ 000016811)

Suarez SS 2008a Control of hyperactivation in sperm. Human Reproduction Update 14 647-657. (doi:10.1093/humupd/dmn029)

Suarez SS $2008 b$ Regulation of sperm storage and movement in the mammalian oviduct. International Journal of Developmental Biology 52 455-462. (doi:10.1387/ijdb.072527ss)

Suarez SS, Revah I, Lo M \& Kolle S 1998 Bull sperm binding to oviductal epithelium is mediated by a $\mathrm{Ca} 2+$-dependent lectin on sperm that recognizes Lewis-a trisaccharide. Biology of Reproduction 59 39-44. (doi:10.1095/biolreprod59.1.39)

Takasaki S, Mizuochi T \& Kobata A 1982 Hydrazinolysis of asparaginelinked sugar chains to produce free oligosaccharides. Methods in Enzymology 83 263-268.
Talevi R \& Gualtieri R 2001 Sulfated glycoconjugates are powerful modulators of bovine sperm adhesion and release from the oviductal epithelium in vitro. Biology of Reproduction 64 491-498. (doi:10.1095/ biolreprod64.2.491)

Tarentino AL \& Plummer TH Jr 1987 Peptide-N4-(N-acetyl- $\beta$-glucosaminyl) asparagine amidase and endo- $\beta-\mathrm{N}$-acetylglucosaminidase from Flavobacterium meningosepticum. Methods in Enzymology 138 770-778.

Thomas PGA, Ignotz GG, Ball BA, Miller PG, Brinsko SP \& Currie B 1995 Isolation, culture, and characterization of equine oviduct epithelial-cells in-vitro. Molecular Reproduction and Development 41 468-478. (doi:10.1002/mrd.1080410409)

Tremoleda JL, Stout TA, Lagutina I, Lazzari G, Bevers MM, Colenbrander B \& Galli C 2003 Effects of in vitro production on horse embryo morphology, cytoskeletal characteristics, and blastocyst capsule formation. Biology of Reproduction 69 1895-1906.

Tsai PS, Garcia-Gil N, van Haeften T \& Gadella BM 2010 How pig sperm prepares to fertilize: stable acrosome docking to the plasma membrane. PLOS ONE 5 e11204. (doi:10.1371/journal.pone.0011204)

Tsai PS, Brewis IA, van Maaren J \& Gadella BM 2012 Involvement of complexin 2 in docking, locking and unlocking of different SNARE complexes during sperm capacitation and induced acrosomal exocytosis. PLoS ONE 7 e32603. (doi:10.1371/journal.pone.0032603)

Varner DD, Forrest DW, Fuentes F, Taylor TS, Hooper RN, Brinsko SP \& Blanchard TL 1991 Measurements of glycosaminoglycans in follicular, oviductal and uterine fluids of mares. Journal of Reproduction and Fertility. Supplement 44 297-306.

Yanagimachi R \& Chang MC 1963 Sperm ascent through the oviduct of the hamster and rabbit in relation to the time of ovulation. Journal of Reproduction and Fertility 6 413-420. (doi:10.1530/jrf.0.0060413)

Yang DH, McMillan AG, Standley NT, Shannon P \& Xu ZZ 2012 Extracellular calcium is involved in egg yolk-induced head-to-head agglutination of bull sperm. Theriogenology 78 1476-1486. (doi:10. 1016/j.theriogenology.2012.06.021)

Zhang H, Li XJ, Martin DB \& Aebersold R 2003 Identification and quantification of $\mathrm{N}$-linked glycoproteins using hydrazide chemistry, stable isotope labeling and mass spectrometry. Nature Biotechnology $\mathbf{2 1}$ 660-666. (doi:10.1038/nbt827)

Received 12 October 2015

First decision 9 November 2015

Revised manuscript received 4 January 2016

Accepted 8 January 2016 